\title{
AMPLIFYING TEACHER VOICE:
}

\section{VETERAN HIGH SCHOOL TEACHERS DURING CCSS IMPLEMENTATION}

\author{
AS A Dissertation submitted to the faculty of \\ 35 \\ 2016 \\ EDD \\ San Francisco State University \\ In partial fulfillment of \\ the requirements for \\ the Degree \\ $\cdot R 4-5$
}

Doctor of Education

In

Educational Leadership

by

Mark Raymond Reibstein

San Francisco, California

January 2016 
Copyright by

Mark Raymond Reibstein

2016 


\section{CERTIFICATION OF APPROVAL}

I certify that I have read Amplifying Teacher Voice: Veteran High School Teachers During CCSS Implementation by Mark Raymond Reibstein, and that in my opinion this work meets the criteria for approving a dissertation submitted in partial fulfillment of the requirement for the degree Doctor of Education in Educational Leadership at San Francisco State University.

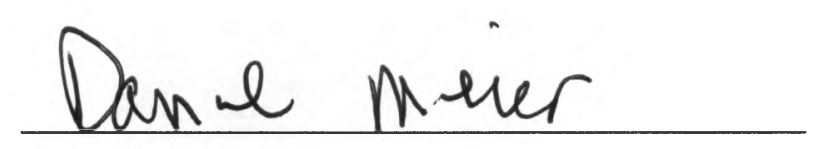

Dr. Daniel Meier

Professor

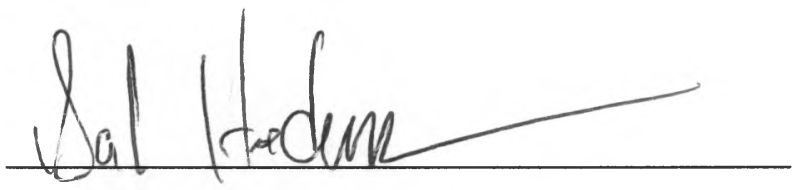

Dr. Barbara Henderson

Professor

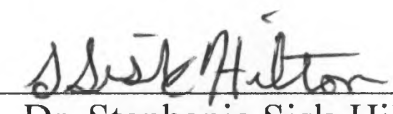

Dr. Stephanie Sisk-Hilton

Associate Professor 


\title{
AMPLIFYING TEACHER VOICE: \\ VETERAN HIGH SCHOOL TEACHERS DURING CCSS IMPLEMENTATION
}

\author{
Mark Raymond Reibstein \\ San Francisco, California \\ 2016
}

This dissertation consists of three linked papers that examine and amplify teachers' voice during Common Core State Standards (CCSS) implementation. Using the framework of narrative inquiry, the first paper explores my own sense of agency and voice over twentyfour years of secondary school teaching in private and public schools as linked to different institutional cultures and to large-scale reform. The second paper examines the experiences and perspectives of seven veteran public school teachers in the Sequoia Union High School District on CCSS implementation and professional development. Using narrative-based interviewing and focus group methodology, the findings show three critical frames that the teachers use to interpret their roles and identities in the process of standards-based and accountability reform efforts. The third paper consists of a set of activities and recommendations for professional development utilizing an original film of the focus group, to be offered to the San Mateo County Office of Education as part of a consultancy partnership to help amplify teacher voice during CCSS implementation.

I certify that the Abstract is a correct representation of the content of this dissertation.

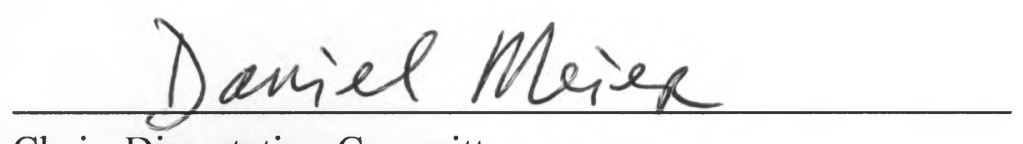

Chair, Dissertation Committee

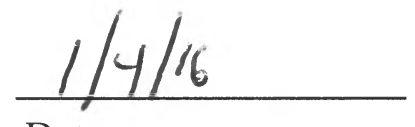

Date 


\section{ACKNOWLEDGMENTS}

I am deeply indebted to my dissertation chair, Dr. Daniel Meier, and the other members of my dissertation committee, Dr. Barbara Henderson and Dr. Stephanie Sisk-Hilton for their patience, positivity, support, and guidance. I am also very grateful for the support and indulgence of Nenette and the rest of my family, my students, my colleagues, the administration at Woodside High School, and Lori Musso of the San Mateo County Office of Education. 


\section{TABLE OF CONTENTS}

List of Appendices.................................................................. viii Part One: From Independent Secondary Education to Standards-Based Reform: My Experiences with Teacher Agency, Voice, and Professionalism ......................1 Narrative Inquiry - Understanding the Professional Trajectory of My Teaching...2

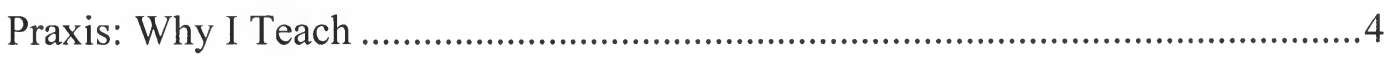

Elite Private Education: Preparation for Leadership ................................................8

Harkness in Public School: Leadership Pedagogy vs. Workplace Rigor?..............14

Teacher Agency: Managerial Culture and Standards and Accountability

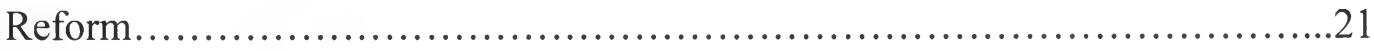

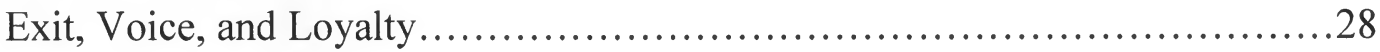

CCSS and Professionalism: Pedagogy at the Center............................31

References............................................................... 40

Part Two: The Wisdom of Practice: Veteran Teachers' Frame CCSS Implementation...45

The Amplification of Teacher Voice in Standards-based Reform ..........................45

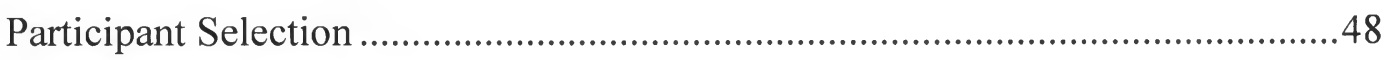

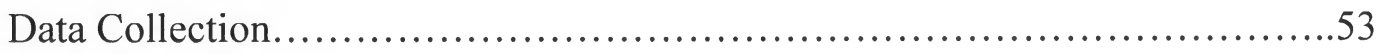

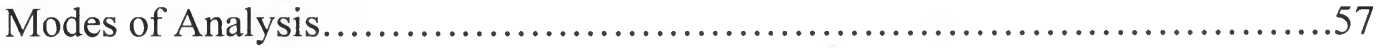

Emergent Frames: The Teacher's Role During Standards-based Reform.........62

Conclusions and Implications...........................................91

References.......................................................... 100 
Part Three: Proposal to San Mateo County Office of Education: Professional Development to Amplify Teachers' Voices During Common Core State Standards

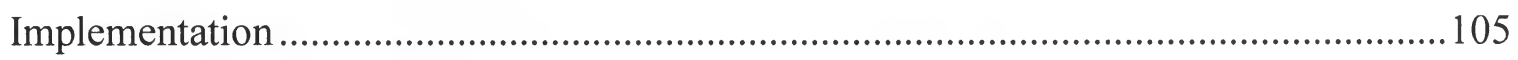
Common Core State Standards (CCSS) Implementation.......................105

The Film: "Time! Trust! Freedom!"..........................................108

Research Foundation.......................................................109

Practical Implications for Professional Development..........................112

SUHSD: Heading in the Right Direction.................................1 114

Proposal for Professional Development: The Double Cohort Framework........116

Other Recommendations for Professional Development Related to CCSS.......124

Reflections.......................................................... 125

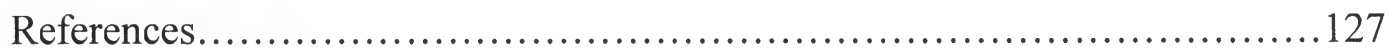

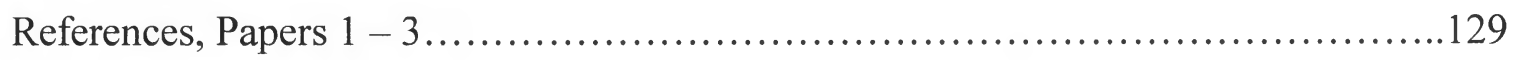

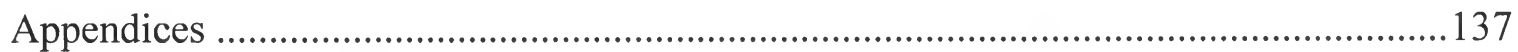




\section{LIST OF APPENDICES}

$\begin{array}{lll}\text { Appendix } & \text { Page }\end{array}$

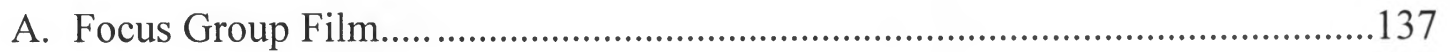

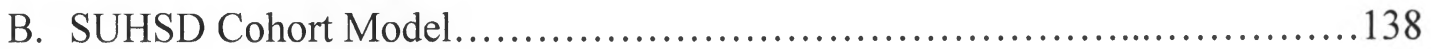

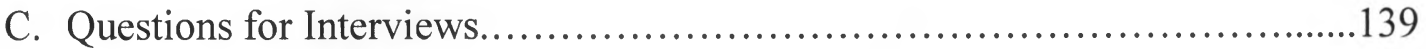

D. Questions for Focus Group............................................................................141 


\section{From Independent Secondary Education to Standards-Based Reform: My Experiences with Teacher Agency, Voice, and Professionalism}

After 20 years of teaching at private and public high schools, I wondered if it was time to stop. For the 13 years that followed my first year of teaching, every year seemed better than the one before it. My sense of my professionalism, my increased agency, and the feedback I received from students, colleagues, administration, and parents all confirmed for me that I was doing the work I wanted to do and that my teaching was improving each year. I took great pleasure in teaching as both craft and service. During those 13 years, I was teaching in elite private high schools. Aware that the need for service was more pressing in public education, I took a high school teaching position at a public school. After six years, I realized that my sense of professionalism and agency had declined with every passing year. Did my age - or my temperament - render me unable to meet the greater demands of public education? Were the problems I faced mostly my own, or were these systemic issues, which might be affecting other teachers, as well? I had clear goals for my students at this public school; how much did my difficulties suggest that those goals were unachievable or undesirable there? Three years ago, I decided I was not through - at least not until I'd figured out what had happened, so that I might try to do something about it. So I began my doctoral studies, wherein I have explored some of the different cultural histories between public and private schools, and, 
by examining the policy reforms implemented during my tenure in public schools, I have tried to better understand why I perceived my role in independent schools as focused primarily on pedagogy, whereas, too often, I have experienced my role in public schools as instrumental and with a decreased sense of autonomy.

\section{Narrative Inquiry - Understanding the Professional Trajectory of My Teaching}

The present narrative seeks to contextualize my experiences historically with a discussion of school cultures and the standards-based reform movement currently impacting public education (McGill, 2015; Ravitch, 2013). In doing so, I rely on the qualitative educational research framework of narrative inquiry (Clandinin \& Connelly, 2000), which uses story and memoir to make visible the personal and professional lives of teachers and others in schools, and to illuminate key experiences, perspectives, and values of educators. In particular, I am interested in uncovering my experiences and perspectives on teacher agency and voice, and their connection to how I understand my professional role and capacities. In its interrogation of the standards and accountability movement's framing of the role of the teacher upon my own experiences, this paper is also a counter-story (Giroux, 1996; Polkinghorne, 1988) set against the dominant narrative of educational reform as top-down, driven by policy-makers and politicians for administrators and teachers to implement (McGill, 2015; Ravitch, 2013). Teachers' intentions, successes, and struggles are not voiced in that narrative. My scholarly 
personal narrative (Nash, 2004; Reddick \& Saenz, 2012) of my work in schools over the last twenty-four years seeks to reclaim my place and that of my colleagues in public education as knowledgeable, critical professionals, pursuing equity in our work by striving to meet students' needs within the evolving contexts of institutional and policy expectations.

The call for narrative inquiry's significance in school reform discourse is consistent with a movement away from grand narrative solutions, following recognition of the importance of complex, local conditions and actors within pragmatic discussions of implementation (Clandinin \& Connelly, 1998). Pioneers of narrative inquiry, Clandinin and Connelly (1998), seek to give primacy to the concerns and knowledge of teachers, insiders who work at the intersection of theory and practice, but whose practice rarely shapes that theory. Clandinin and Connelly argue that narrative inquiry is well suited to "make spaces for [teachers'] unheard voices" (p. 152). As a methodological approach that centralizes experience over time and place, narrative inquiry has the potential to link the assessment and development of educational policy with the particular stories and perspectives of practitioners in classrooms.

This is neither a psychological self-portrait nor a set of sociological profiles of institutions; I seek instead to inform my experience by employing the three-part methodology for narrative inquiry outlined by Clandinin (2006), based upon constructs of experience formulated by the pragmatist philosopher and educator, John Dewey. The first 
dimension of experience, identified as relational or personal and social, constitutes the core of my narrative, as I describe my relationship with teaching and learning from the very first time I conceived of being a teacher until today. I identify motives, highlights, and low points to better understand the increased sense of agency, voice, and professionalism that characterized my first 14 years of teaching and also the sense of diminishment that followed, in my first six years in public school, followed by a recent renewal of feelings of efficacy.

As I consider what changed for me and in educational reform writ-large over time, my narrative explores the second dimension of experience - the temporal and continual - although my focus remains personal, as I am interested in the impact of these environments on my own agency, voice, and professionalism. The discussion of those environments (institutional cultures and the larger standards and accountability reform movement) extends my narrative in Clandinin's (2006) third dimension: spatial.

\section{Praxis: Why I Teach}

John Dewey's (1916) philosophy of education has always resonated for me, articulating what I already considered the "what" and "why" of teaching and learning before I had ever heard of him. My first experience with the craft of teaching came at an early age. Invited to help a young man with an experiment, I was one of three sixth graders brought to a class of fourth graders and asked to teach a lesson. I watched the 
students' faces as the first one of us proceeded. Clearly, the students were too bored to learn anything. The second, my friend who was already an aspiring actor and comedian, had them rolling in their seats. But although they loved him, it was also clear that they hadn't learned anything. During my own turn, I kept watching the students, working hard to both maintain interest and relate information clearly, and I could see that they were getting it. It occurred to me that this was something at which I might be good - and it wasn't easy. I also knew that I had succeeded because I had negotiated between the interests of the students and the prescribed lesson, rather than doing what my peers had done: ignoring one in order to satisfy the other.

In essence, this is an expression of the role of the teacher as defined by John Dewey (1916): a negotiator between students' needs and institutional or academic demands. A pragmatist, Dewey (1933) understood human experience as something like continual problem-solving - meaning-making is what we do every day, based upon investigation, experimentation, strategizing, and acting for improved circumstances. Learning could and should be an organic expression of those processes, which begin with interest -- perhaps created by a problem, or perhaps by a desire. But teaching is also a social process in that it is how a person or society passes on desirable values, skills, and information. A teacher has the simultaneous goals of individualizing and socializing. These can come in conflict with each other, but Dewey (1916) was a believer in creative tensions. Teachers' professionalism, as he understood it, was to some extent a measure of 
how skillfully the extraordinarily complex, dynamic, and responsive craft of resolving that tension in the best interests of individuals and society was practiced. A great deal was at stake for Dewey (1916), as well, in terms of the quality of teaching and learning. The success of democracy, understood as more than just a political process but a form of living involving freedom of association and self-determination, hinged upon whether education became this responsive negotiation or was reduced to merely a transfer of information. The latter would create docile, vulnerable, poorly informed followers unable to care for themselves or challenge an inequitable status quo. But students who had been taught to negotiate their needs with larger social demands would have the critical capacities, access to information, and social skills to remake society and solve problems collaboratively.

As a high school senior, I conducted an independent study in education. I returned to assist the same sixth-grade teacher who had volunteered me for that teaching experiment, student-taught with her, and wrote a paper based upon guided readings. One of the books I read was Paolo Freire's (1970) Pedagogy of the Oppressed. The shouts for revolution heard in this book's year of publication still rang in my ears. My heroes had been my older brothers and sister and their peers, who had mobilized to protest the Vietnam War, but I understood that a different kind of war continued every day for many people whose existence was a struggle, and that the world still needed radical change. I recognized, in Freire's critique of a "banking pedagogy," essentially the realization of 
Dewey's anti-democratic dystopia. With learning treated as a commodity to be transferred, critical thinking stifled, and students lined up, herded, sorted, and placed in the workforce or leadership positions to maintain the status quo - or in great numbers excluded altogether from participation - the system protected itself from change. But Freire gave us an alternative: responsive, problem-solving education, which changed power relationships between teachers and learners. Most of this perspective was present in Deweyan philosophy, but in Freire, sifted through Christianity and Marxism, it had matured politically and poetically, as he proposed a pedagogy that would liberate, unite, and humanize. He reconceived education as a revolution of love, dignifying all parties. If inklings of Dewey's democratic ideal had made Dr. Martin Luther King Jr. possible, this was what Dr. King preached. Though the classroom seemed a humble place to work, I was convinced that worlds were being made and could be remade there.

After college, I enjoyed several jobs working with young people in therapeutic settings, work crews, summer camps, and wilderness expeditions, but when Ronald Reagan was elected President it seemed, in the singer Gil Scott Heron's words, to be "Winter in America" for the under-privileged. Deciding battles beyond the classroom needed fighting, I enrolled in a law school dedicated to public interest law. Two years later, while providing legal aid services for residents of New York's Chinatown, I had a discussion with one of the partners, a leader in the National Lawyer's Guild. When he told me, "Don't do this work to save the world, Mark. Do it because you love it," I 
immediately thought of teaching. I could only conceive of legal work as a kind of sacrifice, but teaching for me was a creative act.

\section{Elite Private Education: Preparation for Leadership}

Three years later, I was hoping to get my first job as a public school teacher in Richmond, California, where I had student-taught while earning a credential at the University of California at Berkeley. A shooting on campus, ex-convicts in my classroom, and the economic circumstances most students there struggled with convinced me it was a perfect place to try some world-creation. It was late August; the Richmond school district was still not hiring, and I received a call from the 'Iolani School in Hawaii. I had used the school's Dean of Faculty and School Head for interviewing practice when they had come on campus. The job was hard to turn down, principally because I had no other. 'Iolani is an elite private school, where small classes consist of Oahu's most academically driven students. The job was difficult to reconcile with my social-service goals, but what I told myself was not that different from what some of my friends in law school had said, as they accepted jobs in the corporate sector: "I'll learn what I can there, to bring back to public service." I figured I would learn about my own abilities in a school where academic excellence was the norm. From students achieving at the highest levels, I would learn what public high school students might also achieve. 
On the day before my first day of teaching, a colleague gave a presentation on something she had learned about during a summer fellowship. It was the Harkness discussion (Phillips, 2015), a method that for the past 100 years has been the defining pedagogy at Phillips Exeter Academy, an elite, independent feeder school for Harvard University. This method would shape my own pedagogy from that day forward. It is in many respects similar to the Socratic discussions in International Baccalaureate programs, but whereas the inquiry in Socratic discussions remains teacher-driven, the ultimate goal in a Harkness discussion is for students to take the wheel, initiating and sustaining text-focused inquiry. A lot of training and teacher-driving remains a part of Harkness pedagogy, but the goal is always for students to arrive at meaningful destinations through self-navigation.

It was a teaching method that also immediately struck me as having the potential to fulfill Dewey's notion of the teacher's role. Traditional classroom power dynamics shift when students' inquiry takes center-stage and the teacher guides, but is no longer the sole source of wisdom or authority. Students are encouraged to value their own knowledge, while being challenged to learn more. Teaching and learning are organically situated in the social relationships that already mean so much to adolescents. Speaking, listening, and collaborating skills, invaluable tools for meeting their own life-long needs as well as for democratic problem-solving, could become texts-in-themselves, where students might learn through action and teacher-prompted reflection. In shared inquiry 
and analysis, students operating at higher academic levels modeled skills for their classmates, learning from them as well about new ways to see or experience things. For me, this evoked the campfires and group meetings where the young people I'd worked with had learned about themselves and each other, opening up to new experiences and perspectives. Harkness discussions were small, occurring around oval tables. So different from the rows of teacher-facing chairs to be found in all other American classrooms, this arrangement realized a democratic ethos. This was an education to which students had to bring their whole selves, giving a teacher so many more opportunities to assess needs and make learning meaningful.

But 'Iolani is not Exeter. At Exeter, Harkness was a competitive sport, complete with the pursuit of dominance one might find on a football field. Exeter had been allmale for decades and still served New England's academic elite. Emerging from cultural traditions of assertive individualism, the ethos of the discussion there seemed to reinforce the defense of privilege. The Harkness table resembled an executive boardroom - a place for self-assurance, agency, and the other attributes of leadership in a capitalist society. Students staked ground, attacked, defended, and then crushed opponents. At 'Iolani, on the other hand, most students claimed that an Asian cultural heritage had taught them, "The nail that sticks up gets hammered down." They may have been comfortable with their privilege, but the signs of that were discretion and face-saving for those you might otherwise dominate or ignore. They could write brilliant arguments, but they hesitated to 
challenge each other in public. This contributed to my development of a different model for the Harkness discussion at 'Iolani - one that was collaborative instead of competitive, and which centered upon critical inquiry, rather than argument. When the Dean of Faculty at 'Iolani, an Exeter alumnus, came to observe my teaching, he made it clear that what he saw was not the hard-edged, intimidating activity he had known as Harkness. I realized then I was doing something new, more student-driven and inclusive, and I sensed it had important applications elsewhere.

It was at the Masters School, an elite private school in New York, that I was to experience the potential of Harkness as I had conceived of it, realized eventually in virtually every classroom and by the school's culture as a whole. After teaching abroad for a few years upon leaving Iolani, I had returned to the U.S. mainland and once again had accepted a private school job out of necessity, while waiting for a public school job to come through. Coming on campus for long-term substitute work, I was surprised to learn that The Masters School had just become the first school outside of Exeter to purchase Harkness tables and adopt the method. Perhaps relating to its long history as a girls' school (boys were introduced with the Harkness tables) and to the school's proximity to New York City, there was interest in a model for Harkness that would be far more collaborative and inclusive than the one at Exeter. The Masters School valued diversity of all kinds - ethnic, economic, and national, as well as of perspectives and talents. Listening to and supporting others was as important as speaking up for one's 
self, and students with points of view often marginalized were encouraged to find their voices. The Harkness tables genuinely seemed to focus the community as a whole around teaching and learning through inquiry, collaboration, and support. Interestingly, on a visit to Exeter in 1998, I was surprised to see that the model for Harkness was changing there as well, as many teachers were beginning to approach it collaboratively; this has continued to be the case as other schools have adopted the method.

At Masters, I felt as though I had agency and voice as a teacher, because the enterprise in which I was engaged was so clearly the collective focus of everyone on campus. Administrators were very present and aware of what went on in classrooms, although they deferred to department heads' and teachers' authority, as if in recognition that it was the most important work occurring there. The ground we shared was our commitment to meeting students' needs, as those arose in all their individualized, multiple forms. In my first years there, the entire faculty would discuss every student in the school six times during the school year. When the school doubled in size this became impossible, but there were still meetings six times a year where struggling students were discussed by every teacher who taught them. Aside from the school's frequent cultural events, most meetings were devoted to students, pedagogy, or policy - and in those meetings, teachers' opinions were always solicited.

Faculty at Masters School were urged to make classrooms exciting places, where we might bring our own passions to bear. There were multiple opportunities to create 
new curricula and interdisciplinary projects, contextualizing academic learning in reallife activities and addressing problems outside of school. This was an education that prepared students, through collective problem-solving and critical thought, for the challenges of democracy. We teachers modeled democratic processes as well, because changes were not experienced as the top-down implementation of ideas or compliance with regulations from without. New initiatives and curricula were often developed at the department level, inspired by ideas to better meet students' needs, and the Academic Committee, a representative body consisting of department heads, worked closely with the administration to assess progress and procedures, giving the school a clear and shared sense of direction.

At Masters, the school community seemed collectively focused on meeting students' needs. Richard Elmore (2008) has clarified how teachers' collective responsibility for the instructional core is critical to school improvement. But whereas this has led many reformers to espouse tighter organizational controls over teachers' classroom activity (Elmore, 2008; McGill, 2015; Ravitch, 2010), the cultural norm at Masters reinforced the sense that teachers were the professionals who knew best how to make great learning happen. This was consistent with other cultural norms that reinforced democratic values. Through community service, the many cultural events around which we gathered, the full integration of scholarship and international students, and the work in classes and projects, students were encouraged to interrogate privilege 
and question the equity and social justice of the status quo. I felt that I was participating in the kind of education all students deserved, and which I still hoped someday to bring to students who did not have social and economic access to an elite private school.

\section{Harkness in Public School: Leadership Pedagogy vs. Workplace Rigor?}

A move to California finally made it possible for me work in public schools, where I knew students' needs were greater, when I was hired by Woodside High School (WHS) in the Sequoia Union High School District (SUHSD). Given the years of experience I brought as a teacher, I hoped to be one of many problem-solvers, reassessing systems and procedures, encouraged to innovate and valued for doing so, as I had been in the independent school world. Now in my tenth year teaching English at Woodside High School, I feel as though I am only just beginning to learn how to structure and support student-based learning, teaching from a place of agency and autonomy, while sustaining intellectual rigor.

After fourteen years of teaching to those "upper limits" of achievement in elite private schools, I had become used to students coming in with high levels of investment and academic skills, which I found matched only in the Advanced Placement classes, each of which is two to three times the size of any class at Masters. During my early years at WHS, the numbers were overwhelming; from a total student load of 60 to 75 students at Masters, I had to teach up to 175 students, many of which had physical, 
emotional, and social needs rarely seen at Masters. It was not an unexpected change, but I had also hoped to find a high level of collaborative engagement with colleagues to improve our teaching and solve the problems we and our students faced every day. This collaboration exists, but I am still trying to identify the many factors that make it more difficult and qualitatively different than the collaboration I experienced in my private school teaching. Perhaps most significant is that it is subject to more external controls, and there are more formidable challenges to creating the time or space for open-ended problem-framing and collaborative problem-solving. Large classes, student alienation, and the sometimes overwhelming demands resulting from other problems related to social inequities in schools and the world outside often isolate teachers as we struggle to manage all the social conditions at play in a classroom. It was rare that I felt I had the time, or that there was much support, for collaborative innovation. I began, therefore, to attempt the reforms I thought were necessary on my own.

The first problem on my agenda was to figure out how I might bring Harkness, which works ideally with about 12 students, to classes of 36 . I split my class in two, creating a "fishbowl," where one group of 18 students would observe the other group, take notes, and advise the first group on process - then the groups would switch. This worked with Advanced Placement English students, but was only modestly successful in the mainstream (classes that were neither Advanced Placement nor intensive support classes). There were triumphs - students who were particularly invested in this kind of 
learning and development, who thrived as leaders and modeled success for others, drawing them in as well. But there were also many students who dug in their heels, with no intention of challenging themselves in ways they had never been asked to before; what I was asking for was not recognizable to them as school. There were, however, some successes even among those - I remember one mainstream student who used to sit in the Harkness discussions, looking into her compact mirror, adjusting her make-up (until I would ask her to put it away). On the last day of class, she held up a graduate level text instead, unpacking it with focused inquiry and analysis (a dense paragraph from Pedagogy of the Oppressed). She swelled with pride, when, in my analysis of the discussion, I praised her high level of engagement. But though successes like these were frequent, they were not the norm. When there are 170 students, it is hard for anything individualized and socially constructed newly everyday to become normative.

On many days, my students rose beautifully to the expectations of the Harkness discussion, saying everything I would have said about the literature, and more that I would not have. They opened it up for themselves and gave me opportunities to speak about it in terms that they had identified as meaningful. There were always students who had remarkable organizational, social, or verbal skills, delighted to have the chance to step forward, lead, and succeed, and this included students who might still be struggling with reading or with English itself. Tortilla Curtain (Boyle, 1996), a novel dealing with immigration, elicited several family stories from students who might not otherwise have 
found the confidence or opportunity to share. I was not putting students on the spot; they were offering their own experiences and discovering unexpected authority. Gloria wrote me a beautiful letter just after finishing another class's final exam, about how our previous day's discussion had crystallized everything we'd talked about all year, and how all that connected with material she had learned in other classes, as well -- she was just then realizing it and wanted me to know.

I often meet students in the community a few years after they graduate, who thank me. Nicholas had been a shy student who learned to speak up in my class. When I saw him just a few weeks ago, he told me how prepared he was for college seminars because of our class discussions. I know that many students are grateful to have learned so much about their own abilities in the Harkness discussions. Different classes had distinctly different personalities, and I have learned to adjust accordingly, arranging groups that I thought would click, changing group size and varying activities. The Advanced Placement students' discussions have always been reliably good. Students in all classes routinely tell me that mine is their favorite class. I sometimes suspect, however, that there are whispers about this from some other teachers and perhaps students as well, as I fear that some regard a student's ability to improve grades substantially, through discussion, as indicative of a lack of rigor. If this is true, it may yet be about to change, as CCSS give new prominence to speaking and listening skills. 
Unfortunately, there were times when my classes did lack rigor, when the social agreements upon which they relied broke down. For me to genuinely give students the authority over their own learning that Harkness teaching requires, it was necessary for me to relax some of my control over the class. But a teacher's micro-authority can only be suspended if students recognize a teacher's ultimate authority to keep the environment safe, focused, and academically challenging. I can be an intellectual coach only if I am not forced, perpetually, to referee. In Advanced Placement classes, students had enough of a stake in meeting the expectations of the teacher, parents, the institution, and perhaps in learning itself, so that, despite the large class sizes, behavior problems were as rare as they had been when I taught in private schools. In several other classes, however, personalities could be too strong, too accustomed to confrontation, or too unwilling to adopt the academic seriousness needed for focused collaborative inquiry. I was surprised, in my first year, to encounter what I interpreted as outright hostility towards me from some students, which seemed to come from the nature of my expectations for them. They had come a long way, it seemed, accepting only that teachers were there to demand obedience and pass on information. They had no intention of giving teachers anything other than what they were forced to give, particularly if that teacher was fool enough to relinquish his own control.

Some colleagues reacted with mild interest to what I was attempting to do; many were unaware; and some seemed to regard it as some kind of private school pretension or 
mis-estimation of public school students' needs and capacities. My department head seemed dismissive. Although I had been a department head for six years at Masters, and had trained an entire department in the use of this method, I was never asked to speak at Woodside about what I was doing or to offer advice to others in my department. In this way, I realized how self-perpetuating the logic of the large public school classroom could be, particularly in mainstream or special needs classes: it is impossible to get anything done without order, and some teachers have found that the best way to maintain order is to line up the desks, keep students' interactions with each other at a minimum, and thereby limit one's teaching, primarily, to giving instructions and information.

Of course, there are many private schools where obedience is just as highly prioritized. Although Masters is a highly selective, elite private school, I had experienced there the kind of democratic education that I thought every student should have. I continue to believe that, although I may not have known how best to solicit support and collaboration, to have given up on Harkness during my early years at WHS would have been a mistake. To do so, I thought, would have meant giving up on my students and myself. I did not think my students and I could learn something new unless we were exposed to it and practiced it together. These were students who had long been taught to follow, but they deserved to learn how to lead and to take themselves seriously as learners. I had come to public school teaching hoping to provide opportunities for students to experience learning as organic, self-navigated inquiry, rather than just a task 
they were forced to complete. The expected and generally practiced model of secondary education seemed to me to be only half of what Dewey identified as the teaching dynamic: socialization. I wanted to provide more opportunities for students to individualize their learning, to function as collaborative problem-solvers, and, for this, I needed to increase student agency and voice. I had also discovered my own agency and voice as a teacher through Harkness; and I think much of what happens between a teacher and students is and must be personal in this way. I felt I could help students negotiate this journey, because it had been my own. My students' struggles suggested to me the seriousness of their needs, and my early failures at WHS strengthened my resolve to eventually get things right.

In the past two years, I have had considerably greater success with the mainstream seniors. I adapted some of what I learned in a professional development workshop on new technologies and a teaching model used in intensive support classes, dividing my class into three parts and rotating students during a single period. On the computers, students complete assigned work. In small groups, they prepare for discussion. In a 12person discussion "diamond," which I join and which no longer has the fishbowl effect of raising pressure and self-consciousness, students have Harkness discussions similar to those I led at the Masters school. Distracting behavior in any of the groups is less likely to throw everyone else off track; there are many non-disruptive avenues for productive work and social interaction, and I can focus on the shared inquiry of 12 students for one- 
third of the class. These changes in pedagogy have done much to restore my sense of efficacy in the classroom, giving me once again the feeling that I am promoting problemposing (Freire, 1970) and collaborative dialogue to create a more democratic classroom (Dewey, 1916) for the students and for myself.

\section{Teacher Agency: Managerial Culture and Standards and Accountability Reform}

I have always had great respect for my colleagues at WHS. In the past few years, I have been lucky enough to be part of two academies within the school, which group students and teachers together; and in these academies, we do practice much of the collaboration, interdisciplinary learning, and student-focused pedagogy I seek. These academies have potential; but, again, their impact on the school culture-at-large appears limited, and because they must operate within that culture, the time and flexibility needed to truly innovate is limited. For years, I have also collaborated with other veteran teachers on an interdisciplinary research project. On the one hand, this project does exactly what I think is necessary: students' learning becomes individualized to the extent that they choose their own subjects to research, and teachers collaborate across two disciplines (social studies and English) to prepare students and assess their work. On the other hand, for many years this project, more than any other, was one where I felt constant pressure to move in lockstep with other teachers, and many of the students experienced the project in exactly the same way. Somehow, the pleasure of learning or 
presenting information in new ways had been lost, and students' work often seemed tortured, as a result. Only rarely have I felt at WHS what I always felt at Masters, which was that pedagogy, practiced as an art, was the reason for the institution's existence. Surely, this has much to do with the different conditions and purposes of public and elite private high schools, but each world has much to learn from the other, and I have been disappointed to experience resistance, in each world, to looking at what the other has to offer.

Although Masters students were encouraged to question privilege in general terms, both Masters and 'Iolani largely ignored the nearby public schools, as if engaging with those other worlds might, by highlighting common ground, threaten the exceptionalism of the private school's brand. At WHS, I encountered just as much resistance to hearing about private school pedagogy and collaboration. Some of my colleagues routinely dismissed any comparisons I made to private schools as irrelevant. On the one hand, notions of irrelevance seemed to acknowledge that some private school resources and conditions were ideal; on the other, there was an unwillingness to consider what comes of those ideal resources and conditions as potentially instructive. I was searching, as I still am, for a way that I might integrate elements of teacher agency and voice from my private school experiences with my public school teaching.

It was not until my recent doctoral work that I discovered a history of school cultures, which resonated deeply for me, expressing how I had experienced a role change 
in my transition from elite private to public education. During my first 8 years at WHS, I felt that I had gone from being a professional colleague to more of a manager. In their discussion of academic cultures in higher education, William H. Bergquist and Kenneth Pawlak (2008) identify the culture of elite private secondary schools as "collegial," because their purpose was to prepare students for the early colleges. Highly controlled residential environments where the extracurricular was as important as the academic, the collegial culture in both the colleges and their preparation schools was concerned with "the whole range of social life and development... Faculty and students were judged on their manner of thought and discourse rather than on the basis of any specific body of knowledge" (p. 17). Collegial cultures individualize learning, because they serve the elite, and some degrees of independent thinking are necessary for leadership and the enjoyment of privilege. In collegial culture, a teacher is expected to model that independent thought. Today, elite private schools remain shaped by collegial cultures, and I experienced this in both of the independent schools where I taught. One coincidence of my years in both 'Iolani and Masters was that I found in my mailbox at both schools a photocopied passage from a book by Robertson Davies (1981), wherein the author makes a plea for eccentricity in teaching. Above all, says Davies, don't be boring or predictable. The Academic Dean at 'Iolani and my Department Head at Masters had both passed the passage on. But this expressed something I understood from alumni, as well. In a collegial culture, teachers' particular strengths and personal 
passions are treasured assets, foundational to that school's identity and success for students and teachers over time.

The collegial culture has historically served those who have access to social privilege, economic means, and the expectation of leadership. Bergquist and Pawlak (2008) argue that the more common educational culture since the latter half of the last century is "managerial" (p. 43), which originated in elementary and secondary education and has continued to shape those worlds. At the turn of the last century, schools at every level were responding to a huge influx of immigrants. Two characteristics emerged from this history to shape the ethos of public schools: 1) a sense of mission and service regarding the newly arrived and the very needy, whose status as outsiders made assimilation and employment central concerns, and 2) clear lines of authority and obedience arising from the "accepted hierarchy of the teaching orders and the church... [with] formally designated administrators of the institution [having] control over the planning and managerial functions..." (p. 44). The great numbers of students, the methods used to herd and sort them, the simplified curricula and vocational focus were considered signs of democratization, increasing access to education for the previously excluded. The teacher, as manager, helps students proceed obediently from one clearly defined step to another. The values held at a premium in this culture, for both teachers and students, are competence and efficiency. 
The managerial culture became central and enduring in public education when hierarchical power structures and curricula were standardized in the early decades of the last century, wresting control from localized school boards and community schools in order to professionalize teaching (McGill, 2015; Tyack \& Cuban, 1995). Just as they have today, progressives on the left united with conservatives in the business community around a model for school reform promising social and economic inclusion for excluded Americans. It took its cue from the factories' new assembly-lines, organizing all of the facts needed into a set body of knowledge and dividing it up in the 12 years of schooling, doling out information through graded textbooks and testing it regularly... This transmission-oriented curriculum was designed to be delivered in large, impersonal factorymodel schools that passed students off from year to year and, by junior high school, from subject area to subject area every 50 minutes (DarlingHammond, 2010, p. 4).

At WHS, I did have some opportunities to create new learning experiences with my colleagues, but there were far fewer opportunities, far more bureaucratic hurdles, and change was far less likely to occur if did not originate at the top than had been my experience in private education. My sense of diminished teacher agency, moreover, increased during my first six years of teaching at WHS. One of the reasons I had been hired by WHS was because No Child Left Behind (NCLB) legislation enacted in 2002 had made the hiring of new staff necessary. The school had just been put on "Program Improvement" - a humiliation for the school - and it seemed every intentional act was focused upon meeting the demands of NCLB, lest severe consequences follow. Classes 
and curriculum were restructured and we were given periodic benchmark tests for students, so that they would be well-prepared for the round of testing that would decide our collective fate. The constriction of teachers' autonomy and agency brought on by NCLB in many schools, during those same first six years I spent at WHS, has been described by organizational theorists Olsen and Sexton (2009) as a phenomenon called "threat rigidity," where institutions take on a siege mentality: "structures tighten; centralized control increases; conformity is stressed; accountability and efficiency measures are emphasized; and alternative or innovative thinking is discouraged" (p. 15). NCLB's high-stakes testing and teacher-proof instruction were found to create conditions for threat rigidity, ultimately shaping cultures most in need of improvement. Raised stress levels, lowered cognitive abilities, and further "maladaptive phenomena" (p. 15) increased organizational dysfunction during NCLB implementation.

NCLB characterized a national standards and accountability reform movement that began in the 1980's with the government report, A Nation at Risk (National Commission, 1983), which framed the achievement gap in terms of school and teacher dysfunction (McGill, 2015; Ravitch, 2013). Erick Hanushek (2012), currently a leading source of scholarship for the standards and accountability movement, highlights "bad teachers" rather than ineffective teaching when he claims that "bad teachers cost hundreds of thousands of dollars in lost income and productivity each year that they remain in the classroom... it is not chance but mismanagement that allows ineffective 
teachers to continue harming students" (p. 68). When the solution is to fire bad teachers, rather than supporting struggling ones, money is saved and systemic problems need not be addressed.

In her seminal work, The Good High School, Sara Lawrence Lightfoot (1983) examined six "good" schools, and Lightfoot was:

... struck by the centrality and dominance of teachers and by the careful attention given to their needs. To varying degrees, the teachers in these high schools are recognized as the critical educational authorities... They give shape to what is taught, how it is taught, and in what context it is transmitted... In the worst schools, teachers are demeaned and infantilized by administrators who view them as custodians, guardians, or uninspired technicians (pp. $333-334$ ).

Lightfoot saw the problem as culturally reinforced by publically accepted notions of teachers as passive, self-interested, and lazy as internalized by district and school administrators. Such notions have currency in today's school reform climate, as demonstrated by the success of the film Waiting for Superman (Guggenheim, 2010), which incidentally featured Woodside High School. In the film, Michelle Rhee, then Chancellor of the Washington D.C. Public Schools, characterizes teachers, indulged and self-indulgent, as pitting their own interests against students' needs. In his study of successful, incremental, teacher-based collaborative change in the public schools of Union City, New Jersey, David Kirp (2013) describes the failures of star-quality teacherintimidators like Joe Clark and Michelle Rhee, who attract headlines by playing into negative cultural stereotypes of teachers to impose top-down changes. Both Clark and 
Rhee ultimately damaged the educational systems they attempted to coerce. Not far from the site of the improvement that Kirp described, New Jersey Governor Chris Christie and Mayor Corey Booker accepted a $\$ 100,000,000$ donation from Mark Zuckerberg for the reform of Newark's schools, announced in coordination with the opening of Waiting For Superman. The intent was to create a model for school reform across the country. In The Prize: Who's in Charge of America's Schools? (2015), journalist Dale Russakoff follows most of Zuckerberg's money - into the pockets of consultants - and tracks the community and school dysfunction that arose from those reform efforts. Zuckerberg is now working with public educators in San Mateo County; it is my hope that this is representative of a shift in our culture away from outside hierarchical educational reform, and toward collaboration and dialogue with teachers to meet students' needs and support teacher knowledge and expertise.

\section{Exit, Voice, and Loyalty}

After my first six years at WHS, I thought I might want to leave the public system, because I was not sure how I could participate with colleagues to create a culture valuing teachers' expertise and perspectives on curriculum and educational change. In his research concerning personal reactions to organizations or products deemed inadequate, the political theorist and economist Albert O. Hirschman (1970), identified every free person's choice between "exit" and "voice," the former as disassociation from the 
organization or product (quitting a job or shopping elsewhere) and the latter expressing dissatisfaction and seeking change. Hirschman makes the point, first of all, that exit must actually be a choice - and, admittedly, there were limits upon its availability to me. While I was free to leave for another job, this was the job I had, and material necessity required that I keep it before taking another. But Hirschman points out that voice must also be connected to a sense of efficacy, and for me that was the sticking point. The meaning of voice, Hirschman says, hinges entirely upon the "history of democratic control through the articulation and aggregation of opinions and interests" (p. 55) in an organization; that is, the expression of voice must matter.

My experience teaching in a public school had ironically seemed less democratic than my experiences in elite private schools. In the independent schools, which I had experienced as having a lateral focus on pedagogy, I felt that my voice had been welcomed, and in my first several years teaching at WHS, which I experienced hierarchically, both my agency and voice felt diminished. Hirschman, furthermore, connects democratic qualities within an organization to differences in product. Democratic responsiveness, which increases voice, corresponds to focus on quality of work and product, improving both. Feedback loops continually raise quality and standards, increasing the gap between high quality organizations and their competitors. This dynamic seemed in many respects to account for what I perceived as the reasons for 
differences in educational output between public and private schools - a matter less of resources and capacities than of cultures, as much politics as pedagogy.

I do not, however, believe that private schools are good for American democracy, as I believe that educating our youth should be a shared enterprise, involving free association and the full investment of all citizens. Private education siphons off resources and reinforces privilege, in the one area where our society has the potential to reinvent itself along the lines of Freirean (1970) liberation of both oppressed and oppressor, in the realization of Dewey's (1916) democratic ideal. But my experience has led me to believe that the public school system has a great deal to learn from private schools, wherein I experienced institutional cultures focused upon teaching and learning, which fostered forms of autonomy and growth for teachers and students that promote individual leadership and democratic dialogue. The attention to students made possible through smaller classes and more innovative curricula, the emphasis on critical thinking, and a respect for the teacher as pedagogue were the hallmarks of the independent school cultures in which I had worked, and I know that, to the extent that these good things remain available only to the privileged, they will reinforce that privilege. I was feeling discouraged in public education during my early years at WHS, perhaps unable to meet its demands, but I also felt that returning to private education would reinforce larger inequities and preclude me from more successfully making changes in my WHS teaching. 
According to Hirschman, every member's choice between exit and voice depends not only upon availability of exit, but also upon another potentially mitigating factor: loyalty. If a person's values are basically aligned with those of an organization, that person may choose voice, even when efficacy is not assured. I have remained at WHS for ten years out of loyalty to the students served by public schools and my colleagues there. I have remained because of the idea expressed so clearly by Dewey (1916) that all students' needs must be served if democracy is to succeed - a goal with which private schools are not fundamentally aligned.

\section{CCSS and Professionalism: Pedagogy at the Center}

I now ask myself, how and where to speak? How can I find agency in a time of top-down reform? With the Every Student Succeeds Act replacing NCLB (Green, 2015), and outgoing Secretary of Education Arne Duncan warning against over-testing in schools, national and state educational reform efforts appear to be moving away from the kind of thread rigidity (Olsen \& Sexton, 2009) that early accountability reforms triggered. The Professional Development department in SUHSD now provides time in the form of a "cohort model," (Appendix B) for teachers to develop curricula in small groups of their own choosing, to observe each other, and to train each other. Whereas, under NCLB, the district took teachers out of classrooms to observe trainers from outside the district, and they sent consultants into schools to tell teachers how to teach. 
The Common Core State Standards (CCSS), the major current reform effort in California and over 41 other states, is an outgrowth of the standards and accountability reform movement of the 1990's and 2000's. Although CCSS, like NCLB, is a change imposed on teachers and schools from without, its implementation is an opportunity for teachers like myself to amplify our professional voices and help refocus our institutions upon teacher expertise and pedagogy. The standards themselves, though potentially paired with accountability measures down the road that might compromise teacher authority, do steer teachers towards the teaching of critical thinking, speaking and listening, and problem-solving, and the providing of more real-world contexts for learning (Darling-Hammond, 2012).

Forty-two states and the District of Columbia have adopted the Common Core State Standards (California 2015). But they were hatched in boardrooms by economic and political leaders and developed by hired educational consultants, with classroom teachers playing minimal roles during feedback stages (Schneider, 2015). A state's adoption usually involved two signatures - a Governor and the head of the state's Board of Education. A political process gave rise to CCSS, rather than the concerns of professional educators whose daily work is to serve the needs of students, and who are therefore the most familiar with those needs. Teachers are only now beginning to make themselves heard. Although supportive of the content of the standards, a teachers' union in New York and the State Board of Education in Massachusetts withdrew their support 
from CCSS, complaining of teachers' exclusion from implementation processes and of the need to assess their own students' needs themselves (Corona, 2013). The fact that teachers do, generally, support the content of CCSS is significant. The standards themselves represent a move towards the prioritization of pedagogy. Introduced in many contexts as standards that are "fewer, deeper, and higher" (Hulce, 2013, p. 1), CCSS seem intended to correct previous standards that emphasized the memorization of content knowledge, replacing that mode of learning with more critical thinking and analysis. This, and CCSS's new focus on speaking, listening, media literacy, and learning in realworld contexts for "college and career readiness," (p. 3) seem to redefine the teacher's role from that of a deliverer of curricula to more of a decision-maker in the classroom, operating in alignment with guidelines rather than in fidelity to proscriptions.

"In every strategy of reform," educational researcher and philosopher Lee Shulman (1997) tells us, "the engine of reform - its regulator and its bottleneck - is the classroom teacher" (p. 504). The ultimate measure of CCSS will depend upon how they impact teachers' pedagogy and the extent to which teachers are involved in CCSS implementation. Earlier in his career, Shulman (1984) espoused "loose coupling," wherein reform measures would be adapted by teachers to suit the needs of students as they perceived them, a form of internal accountability, because Shulman understood the need for teachers to make decisions based upon local assessments of changing circumstances and students' needs. Later, Elmore (2008) and others concerned with 
reform implementation objected to loose coupling, arguing that it allowed for teachers to escape the collective responsibility needed for improvement of the educational core. Perhaps effective policy reform requires the kind of creative tension that Dewey (2015) believed was at the heart of teaching, which suffers when either socialization or individualization breaks down. The negotiation between a teacher's perceptions of students' needs and institutional expectations must neither be reduced to that teacher's total freedom nor to that institution's lock-step control. For Shulman, teacher autonomy reflects the necessarily complex negotiation identified by Dewey. The professionalization of teaching, for Shulman (1998), as for Dewey, means the cultivation of wisdom gleaned from practice. This is possible when communities of professional learning are fostered, where teachers give voice to experience, self-monitor, and refine their judgment in practice, collaboratively.

As I continue to seek that community at my institution, I find two models appealing for how we might centralize teacher expertise and pedagogy during CCSS implementation in articles by Monique Cherry-McDaniel (2014) and Shawn Vecellio (2013). Cherry-McDaniel's “Coming Full Circle: A Young Teacher's Journey with the Standards Movement," describes her initially "unhealthy relationship" (p. 93) with state standards, as she used them to structure and guide her first year of teaching in an Ohio high school. Students were moved along through clear and concrete steps with remarkable efficiency, an array of support materials, and constant reference to the 
authority of the standards. In so doing, Cherry-McDaniel alienated her students from the discovery of learning, and insulated herself from perceiving their interests and needs. At last, she realized that for the sake of standards, she had abandoned her own deeply held notions of professional responsibility and behavior. To become truly professional, she resolved to "practice pedagogy," committing to continued development and adapting the standards to "democratic living and learning" (p. 95). From that point on, her teaching became the relational act she always knew it should be, rooted in continued reassessment of students' needs and interests, with the standards used as a tool in the process, rather than as the definitive authority by which she structured classroom learning. Consequently, her students became far more engaged in their learning, and she perceived her teaching as more valuable to them.

In "How Shall I Teach Thee? An Uncommon Pedagogy for the Common Core," Vecellio (2013) recommends approaches to CCSS implementation as "countermeasures to the mistakes we made on the heels of NCLB" (p. 222). Teachers, he claims, must recognize CCSS as an invitation to "become pedagogues." If we are to teach critical thinking, then we must create educational experiences centered upon the problem-solving spoken of by Dewey (1933) and Freire (1970). Vecellio sees in CCSS's articulation of the objective of "college and career readiness," Freire's call to read the world critically, looking for and creating new places to inhabit within it. Vecellio offers multiple examples of this process - from interdisciplinary project work to new ways of thinking 
about assessments with inherent learning value - in response to CCSS's greater, crossdisciplinary sophistication. Underlying Vecellio's recommendation is a critique of institutions that do not make critical and engaging pedagogy possible, by regarding teachers as rote performers of routine tasks, or by inevitably reducing them to this with overwhelming numbers of students, little time, and no authority to create curricula, collaborate, or adapt organizational structures to interdisciplinary needs. When CCSS are understood as an invitation to reassess one's own teaching and the objectives and outcomes of institutions, daily, then professional development, Vecellio suggests, should involve reading someone like Paolo Freire and considering the implications of his work for today's society and schools. Vecellio calls for a "new vision of the professional educator" (p. 240) shared by teachers and those who drive policy and determine the conditions of teachers' work. This professional, who "has the ability to design instruction and assessment so as to benefit student learning and who is vested with the autonomy to do so" (p. 240), is Vecellio's new model for school reform: the pedagogue. I respond to Vecellio's call and Cherry-McDaniel's story because that pedagogue is all I ever wanted to be, and I am convinced it is in the best interests of teachers and students for us to practice our pedagogy with greater professional authority and autonomy. Though challenged by the hierarchical imposition of policy and low levels of trust, which have characterized the standards and accountability movement over the last thirty years, I now rededicate myself to public education, seeking to collaborate and 
innovate with colleagues, in the hope that CCSS is indeed an opportunity for all of us to collaborate, moving the work of the classroom to the forefront of educational reform.

I am hopeful that CCSS's new emphasis on critical thinking and problem-solving, in particular, represents a turn of the wheel towards the professional authority and independence of pedagogues in classrooms. Freire (1970) connected those forms of pedagogy to the shifting of power and to students' learning about how to meet their own needs - that is the work I have always aspired to do. At WHS, I work beside professionals who are dedicated to that same endeavor, whose paramount concerns have always, clearly, been the needs of students. In the next two papers in this collection, I highlight the experiences and perspectives of seven of these veteran teachers on teacher autonomy and pedagogy. I think most of my colleagues teach happily in our district, so I cannot represent my own struggles or dis-satisfactions as their own, and indeed I still have an enormous amount to learn from them. Nor do I wish to be misunderstood as claiming that I have not been involved in collaborative projects or various kinds of teacher-groupings to solve problems and create curricula. These have existed during my years at WHS, they are important parts of the culture there, and I have experienced, through my participation in them, collaborative education as I think it should be. In the end, my desires for change are similar to the reformers in that, despite the goodness of these things I have experienced, I crave more radical change, essentially: much more of these good things, to the point where they create a palpable change of culture inside 
schools. Like many current reformers, I am motivated by a desire to provide students with more than what I think they now have - an education for leadership such as the ones I participated in when I taught in independent schools. I break with the reformers in that I do not think enduring educational improvement will occur until the teaching profession is elevated to the extent that it is leading itself by creating new reforms, utilizing everything learned in classrooms, from and with students, every day.

This present work represents my attempt to become more self-aware as a pedagogue in public education, to increase my own voice and the voices of my colleagues, to increase our personal and collective professional agency. My hope is that all teachers will begin demanding more voice and agency and seek the means to increase both. One goal I have is to try to become more involved in our teachers union. I have not worked hard enough to fight the silo-like isolation of classroom teaching, and I would like the union to become more active in matters of pedagogy, helping us take more control over how our time is organized, class size, and other conditions that have such impact upon pedagogy. I believe teachers need to approach administrators as partners, and it is my hope that we will always be treated as such by administrators. I was enormously encouraged by the interest of the San Mateo County Office of Education in partnering with me, in my research, to amplify teachers' voices during CCSS implementation. That is the intention and substance of the next paper in this collection, which, through interviews and a filmed focus group, attempts to capture some of the 
experiences, hopes, concerns, and ideas of the seven veteran teachers during the standards-based reform with which they have participated. The third part of this dissertation is a film consisting of moments from that focus group, along with recommendations for future professional development, in order to amplify teachers' voices, going forward.

On a last note, in terms of the methodology used in this paper, I now see more clearly see the value of narrative inquiry for the retracing and illuminating of critical elements in my professional journey as a teacher. I now realize more deeply how the social, political, and intellectual worlds of the private schools and the public school in which I have worked have shaped my experiences and my valuing of teacher agency and voice as the foundations for good teaching. Narrative inquiry allowed me to retell and reflect on my trajectory as a veteran teacher, who has taught for 24 years, and how I can manage to teach well, while still yearning for greater collaboration and teacher-led innovation. 


\section{References}

Bergquist, W. \& Pawlak, K. (2008). Engaging the six cultures of the academy.

San Francisco, CA: Jossey-Bass.

Boyle, T. C. (1996). Tortilla curtain. New York: Penguin Books.

California Department of Education. (2015). Common core state standards. Retrieved at: http://www.cde.ca.gov/re/cc.

Cherry-McDaniel, M. (2014). Coming full circle: A young teacher's journey with the standards movement. English Journal, 104(2), 93 - 98.

Clandinin, D. (2006). Narrative inquiry: A methodology for studying lived experience. Research Studies in Music Education, 27(1), 44 - 54.

Clandinin, D. \& Connelly, F. (1998). Stories to live by: Narrative understandings of school reform. Curriculum Inquiry, 28(2), 149 - 164.

Clandinin, D. \& Connelly, F. (2000). Narrative inquiry: Experience and story in qualitative research. San Francisco, CA: Jossey-Bass.

Corona, B. (2013, November 22). More cracks in the core: Massachusetts halts common core implementation. The Daily Signal. Retrieved at: http://dailysignal.com/2013/11/22/cracks-core-massachusetts-halts-common-coreimplementation.

Darling-Hammond, L. (2010). The flat world and education. New York: Teachers College. 
Darling-Hammond, L. (2012). Creating a strong foundation for the teaching career. kappanmagazine.org. (94)3. Retrieved at: http://www.hfhighschool.org/assets/1/7/darlinghammond_the_right_start_pdk_nov_2012.pdf

Davies, R. (1981). The rebel angels. Toronto: Macmillan of Canada.

Dewey, J. (1916). Democracy and education. New York: Macmillan Company.

Dewey, J. (1933). How we think. In Hickman, L. \& Alexander, T. (Eds.). (1998). The essential John Dewey, volume 1: Pragmatism, education, democracy. (pp. 274 277). Bloomington: Indiana University Press.

Elmore, R. (2008). School reform from the inside out. Cambridge, MA: Harvard Education Press.

Freire, P. (1970/2000). Pedagogy of the oppressed. New York: Continuum.

Giroux, H. (1996). Slacking off: Border youth and postmodern education. in Giroux, H., Lankshear, C., McLaren, P., \& Peters, M. (Eds.). (1996) Counternarratives: Cultural studies and critical pedagogies in postmodern spaces (pp. 59 - 80). New York: SUNY Press.

Green, P. (2015, December 11). Duncan on ESEA: Still relentlessly wrong. Huffington Post, Education. Retrieved at: http://www.huffingtonpost.com/petergreene/duncan-on-esea-still-relentless-wrong b 8778996.html.

Guggenheim, D. (2010). Waiting for Superman. U.S.A.: Electric Kinney Films. 
Hanushek, E. (2102). Low-performing teachers have high costs. EducationNext, 4/26/2102. Retrieved at: http://educationnext.org/low-performing-teachers-havehigh-costs/.

Hirschman, A. (1970). Exit, voice and loyalty: Responses to decline in firms, organizations, and states. Cambridge, MA: Harvard University Press.

Hulce, C., Hoehn, N., O'Day, J., \& Walcott, C. (2013). California and the common core state standards: Early steps, early opportunities. Washington, DC: American Institute for Research.

Kirp, D. (2013). Improbable scholars. New York: Oxford University Press.

Lawrence-Lightfoot, S. (1983). The good high school: Portraits of character and culture. U.S.A.: Basic Books, Inc.

McGill, M. (2015). Race to the bottom; Corporate school reform and the future of public education. New York, NY: Teachers College Press.

Nash, R. (2004). Liberating scholarly writing. New York, NY: Teachers College Press. The National Commission on Excellence in Education. (1983). A nation at risk: The imperative for educational reform. Retrieved at: http://www2.ed.gov/pubs/NatAtRisk/index.html.

National Governors Association Center for Best Practices and the Council of Chief State School Officers. (2015). Common Core State Standards Initiative. Retrieved at: http://www.corestandards.org/. 
Olsen, B. \& Sexton, D. (2009). Threat rigidity, school reform, and how teachers view their work inside current educational policy contexts. American Educational Research Journal, 46(1), 9 - 44.

Phillips Exeter Academy. (2015). Harkness. Retrieved at: http://www.exeter.edu/admissions/109 1220.aspx.

Polkinghorne, D. (1988). Narrative knowing and the human sciences. Albany, NY: State University of New York Press.

Ravitch, D. (2010). The death and life of the great American school system: How testing and choice are undermining education. New York: Basic Books.

Ravitch, D. (2013). Reign of error. New York: Knopf.

Reddick, R. and Saenz, V. (2012). Coming home: Hermanos academicos reflect on past and present realities as professors at their alma mater. Harvard Educational Review 82(3), 353-380.

Russakoff, D. (2015). The prize: Who's in charge of America's schools? New York: Houghton Mifflin Publishing Company.

Schneider, M. K. (2015). Common core dilemma: Who owns our schools? New York, NY: Teachers College Press.

Shulman, L. (1983). Autonomy and obligation: The remote control of learning. In Shulman, L. (2004). The wisdom of practice: Essays on teaching, learning, and learning to teach. (pp. 503 - 520). San Francisco: Jossey-Boss. 
Shulman, L. (1997). Professional development: Learning from experience. In Shulman, L. (2004). The wisdom of practice: Essays on teaching, learning, and learning to teach (pp. 133 - 162). San Francisco, CA: Jossey-Bass.

Tyack, D. \& Cuban, L. (1995). Tinkering toward utopia; A century of public school reform. Cambridge, MA: Harvard University Press.

Vecellio, S. (2013). How shall I teach thee? An uncommon pedagogy for the common core. Schools: Studies in Education. 10(2), 222 - 242. 


\title{
The Wisdom of Practice -
}

\section{Veteran Teachers Frame Common Core State Standards Implementation}

\begin{abstract}
Alan (High School Latin Teacher): Right now there are so many newer teachers to the profession. They do whatever is asked of them, without blinking. There's no institutional memory of what education has been or what Woodside was. And also there's no respect for the role or voice of a teacher in these new teachers. Whereas, when you are at a more mature school, the teachers really run the school and they are the ones who add the value to the school and its programs. And were you to clip one of those teachers from that school, you'd be impoverishing the whole school. Here, if everyone is new to the work and everyone says yes to everything, there's tremendous pressure on us older teachers to respond as youthful and compliant newbies to every single additional request.
\end{abstract}

\section{The Amplification of Teacher Voice in Standards-Based Reform}

As school districts across the country implement the Common Core State

Standards (CCSS), it is important to put this moment in educational reform in the larger context of a standards-based and accountability movement reaching back 30 years, to the publication of $A$ Nation at Risk (National Commission on Excellence in Education, 1983), a federally-sponsored publication that framed the national achievement gap as the failure of schools and teachers to demand adequate rigor and create high enough expectations for students (Cuban, 2013; McGill, 2015; Ravitch, 2013). I was interested in examining how a group of highly competent and well-regarded veteran teachers, in a range of disciplines, viewed their roles over the course of educational reform from the California State Standards in 1997 to the current, early stages of CCSS implementation. I had entered public school teaching in 2005, and I was especially interested in examining 
the perspectives of experienced teachers on cycles of education reform efforts, and how and why veteran teachers maintain a sense of autonomy, voice, and agency.

I conducted interviews and a focus group with several veteran teachers in my district, and my research questions focused on:

1) How do veteran teachers' experience their roles, as teachers, in regard to standards-based policies and expectations?

2) How do these teachers view their sense of autonomy and sense of professionalism in connection with educational reform efforts over the last 20 years, with particular emphasis on CCSS implementation?

3) What impact have standards made on their pedagogy, and what are their goals and needs for the future in regard to professional development tied to educational reform?

The overall goal of examining these three central research questions is to amplify teachers' voices during this moment of educational reform, in the hope that ultimately teachers' experiences, concerns, and ideas will become more central to reform discourse. If CCSS implementation is to be successful for students and teachers, the standards and the accompanying professional development activities must align with how teachers view their professional responsibilities and sense of pedagogical autonomy and expertise. The seven teachers I interviewed are the kinds of professionals every school has a great interest in learning from and retaining. They are the "conveyors of culture... the priests 
and priestesses" (Deal \& Peterson, 2009, p. 116) whose expertise, success as models, and social connectedness make them central to the maintenance of traditions, perspectives, and knowledge, and whose familiarity with the levers of power gives them access to change. For these reasons, their experiences and points of view are of particular value to educational reform discourse in general, and for CCSS implementation and professional development at the local level in my district and county.

If teacher-knowledge is to inform educational reform, and both teacher and organizational learning are to occur (Cherry-McDaniel, 2014; Elmore, 2008; Wenger, 1998), then time and space for teachers to have critical conversations must be created by teachers and those who organize teachers' time. If teachers are to assume any degree of leadership over their own profession, then they must not only give voice to their experiences, hopes, and concerns, but find ways to preserve and pass on the results of those conversations (Crowther, Ferguson, \& Hann, 2009; Giroux, 1996; Hargreaves \& Shirley, 2012). They must develop processes for the formulation and analyses of their experiences with students, the problems they face, and ideas for innovation, so that multiple conversations might become the means to highlight salient concerns, generate new ideas, identify conflict, seek agreement, and ultimately affect policy. Reporting on interview and focus group data, this paper gives voice to the perspectives of veteran teachers on professional autonomy and pedagogical excellence as linked to educational reform efforts. The film that accompanies this collection (Appendix A), and which is 
detailed in the third paper, is constructed from highlights of the focus group and provides a structure and tool for professional dialogue and collaboration around CCSS goals and implementation in my district and county.

\section{Participant Selection}

One of the principal criteria for participant selection was years of experience. The range in years of high school teaching experience was between 13 and 35. Because the California State Standards were introduced in 1997 and replaced by CCSS in 2010 (California, 2015), all of the teachers had experienced teaching with state standards and also with the changes brought on by NCLB. Some had also known what teaching without state standards was like. I was specifically interested in the interviewees' views on how teaching with state standards impacted their sense of their professional responsibilities and identities as accomplished teachers, and for teachers to have adequate opportunities to reflect upon themselves as professionals, they must accrue experience over time.

Professionalism implies mastery of subject matter, as well, and I was also seeking teachers who were accomplished representatives of their disciplines. Two of the teachers (aside from myself) are English teachers, two are math teachers, one is a science teacher, one had been a social studies teacher, but is now teaching art, and another had been an English teacher, briefly, and now teaches Latin. English, math, and social studies are the 
disciplines most impacted by CCSS, but all of these teachers have worked with California State Standards in their subject area, and science teachers are anticipating the implementation of new national science standards (California, NGSS, 2015). According to Shulman (1998), professionalism requires "deep understanding, complex practice, ethical conduct, and higher-order learning" (p. 529), and reaching higher levels of professionalism is necessarily a difficult, multi-faceted endeavor. Professionalism for a teacher, as for a doctor or a lawyer, is as complex as the practice itself. Shulman draws upon the work of John Dewey (1904), who thought that "intellectual methods" (p.11) were essential to true professionalism. The teachers who would have the most to contribute to my research, I believed, must be deeply reflective about their work, committed to meeting the needs of students as well as the demands of discipline, institution, and the culture-at-large. In my ten years teaching in the Sequoia Union High School District (SUHSD) in San Mateo County, I had multiple occasions to witness teachers' interactions with students, administrators, colleagues, parents, district personnel, and other community members, in multiple activities, both in and out of classrooms. All of the teachers I chose are colleagues of mine within the same district. Four of them work with me at WHS, two work at Menlo Atherton High School (MAHS), and one works at Sequoia High School (SHS). From my professional contact with these teachers over the years, I determined that they were reflective about their work and the effects of current educational reforms upon their pedagogy. 


\section{The Teachers: Veteran Practitioners from SUHSD}

My interviewees were teachers with substantial experience working with standards. All of them were working in SUHSD for the last five years, during which time CCSS were adopted by the state of California, and all had worked for many years previous to that with the California State Standards. Half of them had also taught for several years without any state standards at all. As I have elaborated above, I sought out high degrees of professionalism, explained above in terms of Dewey's (1904) and Shulman's (1998) ideas, and I looked for these elements in the teachers' lives and work -mastery, comfort, range, and style; a sense of the strengths, potentials, and limits of one's own work; a long view which gets one through rough times; and the appreciation of others for whom and with whom you work.

Dr. Anne Akey, Ph.D., is a colleague at Woodside High School. She has been teaching science for 32 years. Prior to coming to WHS, she taught in Africa with the Peace Corps and in Sacramento's inner city. At WHS, she developed the Advanced Placement Environmental Science class. Many of my Advanced Placement English students were taking her A.P. Environmental Studies classes concurrently, and I had frequent occasions to witness not only their enthusiasm for this teacher and her class, but their engagement with the subject matter, as they brought it into their writing and discussions. 
Under Mr. Alan Eaton, Latin at WHS grew from a single course to the multilevel, five-course program it has become. When he began at WHS, 17 years ago, he also taught English. Alan is not what you might expect of a high school teacher, in that his manner is strikingly reserved, precise, and intellectual. One might wonder how he maintains discipline, but, in fact, students revere him and he has little need for a raised voice or a scolding tone. He will tell you that those things are a waste of valuable teaching time, anyway.

Mr. Abdulhadi Kaddoura has been teaching math for 17 years. He now teaches Algebra II/Trigonometry and Algebra I. Mr. Kaddoura is a favorite among students, because not only is he clear and interesting, and his classes always active and engaging, but he is also very funny. His good will and positivity is something his colleagues appreciate and rely upon, as well.

Ms. Julie Marten began teaching in the Social Studies department 13 years ago and switched to Art after seven years. She introduced "Art Boom," a biannual event that turns the WHS campus into a stage for all kinds of art, from performance to visual. She is also a musician. Ms. Marten is the kind of teacher that students who might otherwise become alienated recognize as on their side - someone with whom they might make a connection. Her commitment to students' interests and her modeling of a life of creative passions makes her contribution to the WHS culture invaluable. 
Dr. Jerry Brodkey, Ph.D., a math teacher for 35 years, taught at MAHS (having just retired at the end of last year). When three of my interviewees at WHS referenced an e-mail he had sent to the entire district, three years earlier, as expressing their own ideas about policy with such restrained eloquence, I began to seek him out and learned more about him from colleagues and students. In fact, Alan Eaton was his student, and he modeled for Alan the power of gentleness, restraint, humor, and care. Alan cites him as a life-long inspiration for him, professionally and personally. Jerry's doctoral work (Brodkey, 1986) was conducted with Larry Cuban and Nel Noddings at Stanford, on the subject of how teachers change.

Liane Strub, an English teacher for 20 years at MAHS, was also an English Department Head and is currently also a Peer Assistance and Review (PAR) representative for SUHSD, in which capacity she is a liaison between the district and the union, to help teachers improve. I have worked with Liane at the district many times over the years, in her capacity as coordinator of activities such as the collaborative grading of practice AP essays by English teachers across the district. Her PAR responsibilities bring her to WHS often, and my daughter, a student at MAHS, informed me that Liane's teaching is highly regarded by students.

Justine Rutigliano teaches English in the International Baccalaureate (IB) program at Sequoia High School (SHS). She has 14 years of experience and last year she won statewide recognition from California's IB administration for her dedication and 
professionalism. She is also a CCSS coordinator at SHS. I completed my interviews with her but, unfortunately, a last-minute obligation prevented her from appearing at the focus group and, therefore, in the film.

\section{Data Collection}

\section{Interviews}

I interviewed all seven teachers individually in their or my classrooms, and in most cases over two visits lasting for approximately two hours total. I adapted the structure of the phenomenological interview (Seidman, 2013) to suit my needs for data. While I was interested, as phenomenological interviewers are, in the "experiences of participants and the meaning they make of that experience" (p. 15), I did not think I needed to go into the depth revealed by Seidman's recommended three-part interview structure, which calls for three sessions of at least an hour and half each. While I did use preliminary questions to uncover these teachers' deepest connections to teaching and the frames that were operational for them, in terms of why they taught, which elements of teaching were most salient for them, and how they understood their professional responsibilities, I did not need to go much further into their life histories or the life events that might have shaped their philosophies, in general. The bulk of the questions (Appendix C) focus on their experiences with standards, as I was most interested in the impact of those experiences on their pedagogy and their capacities to practice with a 
sense of professional autonomy and agency. From my own experience as a teacher in several different high schools and my observations of other teachers, I knew that professional time is a precious commodity for teachers, and time away from work is equally valued. I was reluctant, therefore, to take more of these teachers' time than I needed to answer my research questions satisfactorily.

\section{Focus Group}

After interviewing all the teachers individually about why they taught, how they understood their professional responsibilities in relation to CCSS, and what their needs and hopes were regarding future professional development, I invited all of them to my house for a focus group, informing them that this would be filmed and ultimately offered to the San Mateo County of Office of Education (SMCOE), for potential use by professional development staff, administrators, and teachers throughout the county. All interviewees accepted, but personal circumstances prevented one, at the last minute, from attending. My goals in creating a focus group consisting of the teachers I had already interviewed were multiple, expressed by Kamberelis and Dimitriadis (2008) in their analysis of the potential of focus groups to further purposes of inquiry, pedagogy, and politics; the decision to make the focus group a dinner gathering and to film the event was also an aesthetic one. 
The group was intended to enrich my data and further my investigation of these teachers' framing of their professional experiences and the requirements and potentials of standards because teachers would now have the opportunity to challenge and extend each other's responses. I wanted to raise ideas and themes which had emerged as salient in the interviews, and submit them to further review to see which resonated and were strengthened under collective scrutiny and elaboration, and which consequently faded. The more public nature of the focus group served to further amplify the sense of urgency, commitment, and passion for high-level teaching and creative pedagogy that had arisen in the more private interviews. The fact that the focus group was being filmed, and that the teachers had made the deliberate choice to participate under those circumstances, raised their accountability for and commitment to this more public assertion considerably, particularly because they also knew that this film was being offered to SMCOE to be used professionally, across the district where they worked, and that it might be viewed by their employers and colleagues. I had given every interviewee the choice to be interviewed anonymously and not be filmed, but each had chosen to participate in this activity, and that participation connected with my research goals - to understand and give voice to teachers' deepest professional convictions, hopes, and concerns around teaching and standards-based reform.

I ran the focus group in exactly the same way I run Harkness discussions in my class, out of a commitment to the principle that successful pedagogy must be open-ended 
and reciprocal. There are things I need to learn about my participants, my methods, myself, and the subject matter under consideration, which I can only learn if I surrender some control, increasing the degree to which participants can teach each other and this research can educate, as well. I therefore asked questions (Appendix D), offering my own opinions sparingly. I sought to help participants make connections between each other's comments and between what they were saying in the group and what they had said previously, in the interviews, but I also allowed new emphases to emerge through the social interaction.

In the sense that I hope the film of my focus group might serve as a model for teachers to reduce isolation, increase solidarity, and ultimately seek the means to exercise greater control over their profession, my goals were political. There was also a shaping of the event and a rendering of it, as filmed, which combined the political with the aesthetic, to suggest how events of this type might be situated comfortably within teachers' lives. The focus group was presented as a dinner party. Munching on hors d'oeuvres at sofas, we addressed questions about why we teach. The "meat" of the discussion, concerning standards-based reform, occurred at the dinner table. Dessert, back at the sofas, accompanied wishes and concerns regarding professional development, tied to standardsbased reform. The intention here was not only to create social bonding to bring about unity, but to suggest that teachers' work is a reflection of their social selves and an organic expression of who they are as intellectual and feeling beings, in relation to their 
students, each other, and their educational institutions. Moreover, because the thoughts and feelings that arise from those professional experiences are often undervalued, socially, it is important for teachers to find opportunities to deepen and support the exploration of them. One purpose here was to establish the propriety of teachers' discourse about school reform. Despite the fact that educational policy is critical to teachers' professional work, most policies are discussed and decided upon in arenas beyond teachers' control. One of the ways I tried to highlight the significance of the event, aesthetically, was to have a friend, a film-maker, use high-quality cameras and sound equipment for filming, as opposed to using the kind of video recording equipment to which I and many other non-film-makers have ready access. This was also meant to elevate the significance of the event for the participants, who might feel their statements to be more public and enduring, by virtue of the fact that they were participating in a high-quality film.

\section{Modes of Analysis}

\section{Framing}

The questions I asked in both individual interviews (Appendix C) and in the focus group (Appendix D) were designed to reveal how each teacher framed their own professional responsibilities and what effect standards had on their teaching. In her research on the micro-processes of successful educational reform implementation, 
Cynthia Coburn (2006) illustrates the importance of problem-framing for successful alignment between teacher-behavior and institutional policy. Drawing upon the work of sociologist Erving Goffman, whose Frame Analysis (1974) highlighted the extent to which social behavior is shaped by preconceptions and the interpretation of experience, Coburn highlights the significance of problem-framing for leadership, during reform implementation, by pointing out that leaders can guide teachers to constructive participation by referencing shared frames. My questions sought to highlight, therefore, both alignment and misalignment between how these veteran teachers conceived of what was most important in their professional practice and what they perceived they were being asked to do by standards in general and, more recently, by CCSS in particular. If there were any misalignments, I sought to identify how these teachers resolved any ensuing conflicts.

\section{Coding for Salience}

I approached the analysis of data for the interviews differently than I did the data from the film, but in both cases, I sought salience, in terms of what emerged regarding teachers' framing of their own roles, how they thought standards framed those roles, and what their principal hopes and concerns were regarding state and district requirements and professional development opportunities, going forward. I used two types of codes identified by Bogdan and Biklen (2007) as effective tools for data-analysis: "Subjects" Ways of Thinking about People and Objects" and "Strategy." The former, with markers 
such as "relationship," "authenticity," and "connection," helped me identify the salience of students' needs for these teachers - they thought about their job in terms of human relationship. The identification of common themes, juxtaposed, set up my frame analysis, as, for example, when the desire for more time with colleagues was repeated along with criticism of professional development training from without. From this, I could see that these teachers didn't trust expertise disconnected from the problems they faced every day. Their trust of colleagues, as opposed to experts or administrators, had to do with how they understood their roles as pragmatic problem-solvers requiring both the time and authority to apply standards as needed.

"Strategy" codes helped me identify how teachers approached standards - as in a teacher's desire to "shut the door" or "plan backwards" - and I listened for whether teachers used standards as guides or avoided them altogether. I noticed some markers repeating, but others, surprisingly, disappearing. For example, only Justine Rutigliano and Liane Strub talked about using standards for planning. No teacher mentioned CCSS during the part of the focus group devoted to professional development, indicating to me that although needs arising from CCSS implementation might be significant, they were part of more general concerns and opportunities for improvement.

After each interview, I listened to the recording of each interview all the way through, making written notes of potential key themes and elements related to my three central research questions. In first cycle coding (Saldana, 2013) for "Subjects' Ways of 
Thinking about People and Things" and "Strategy" (Bogden \& Biklen, 2007), I noted some themes emerging quickly, through consensus - for example, the fact that teaching was, first and foremost, a human and relational act for these teachers. Every teacher also expressed the desire for more time to collaborate with colleagues. Some emergent themes, however, suggested more complexity. While there was much agreement with the pedagogical ideas and practices CCSS promote, there were underlying issues with standards themselves and with district policies. As I looked for repeating themes, the "shut door" emerged clearly, and I also looked for where else tensions seemed evident. This was easier to identify in the focus group, using narrative coding (Saldana, 2013) to identify tension between teachers, but I began to note internal tensions revealed in some interviews through frequently used qualifiers, along the lines of "We'll have to see how it shakes out," or "I'm afraid it will all be thrown away again," etc. Through second cycle coding (Saldana, 2013), it became clear to me that teachers' concerns about current largescale reforms ("edu-business," technology, etc.) connected with their concerns about overly-proscriptive district policies in that there were underlying issues of trust.

\section{Narrative in Film}

I used narrative coding (Bogdan \& Biklen, 2007; Saldana, 2013) to analyze the film data, and looked especially for evidence of "individual and unique human action" (Saldana, 2013, p. 134). To begin with, I could reference social interactions such as 
physical or oral affirmation, disagreement, or doubt, in response to comments made. As I made editing decisions to identify and streamline the narrative structure of the event as a whole, salience arose when ideas were repeated or recast, there was pronounced affirmation or debate, or clear thematic connections were made between comments. I watched and re-watched the raw footage to identify the events' narrative elements - the exposition of characters, for instance, or the rise of tensions, to some degree between participants, but more significantly with the educational policies under discussion. Something like a climax occurred when these two types of tension combined in a discussion about technology, which followed one about edu-business and the future of the profession. Disagreement surfaced about how obliged teachers were to respond to the changing world outside their classrooms, manifesting underlying issues of trust - both the lack of trust teachers had in what was coming at them from without, and the lack of trust they felt was placed in them to do their jobs. There was some resolution at the end of the evening, as teachers largely united in their disapproval of educational consultants and administrators who don't teach, advising or evaluating teacher's work, and then identified what would represent ideal directions for professional development. These points in the evening took on salience, emerging as they did to provide the entire event with a compelling narrative structure.

In her discussion of portraiture, a descriptive method she used to capture critical elements of good schooling, Sara Lawrence Lightfoot (1983) argues that a fuller 
conception of a complex subject becomes understandable and communicable due to the "shaping hand of the artist... defining the canvas and shaping the connections among central themes... [in order to] capture the insiders' views of what is important" (p.14). In her work with marginalized youth given the opportunity to make films, Erica Rosenfeld Halverson (2010) pointed to how the use of editing and cinematography, particularly important in the shaping of filmic narrative, can reveal a filmmaker's identity. Reconstructing the event in compelling and concise narrative terms, to create a small portrait of this one group of teachers gathering together, as I had experienced it, involved aesthetic choices, but it was also important to me not to misrepresent the views and words of the participants, or to use their participation in ways with which they were not comfortable. In addition to being fully informed of the purposes of the filming before they agreed to participate, all teachers signed releases and statements after viewing the film, attesting to the fact that I had represented their opinions accurately and that they approved of the film's potential use by the SMCOE for the purposes of professional development.

\section{Emergent Frames: The Teacher's Role During Standards-based Reform}

In the course of my interviews and the subsequent focus group conducted with these seven teachers, three dominant frames (Goffman, 1974; Coburn, 2006) emerged, 
relating to how these teachers perceived their roles, as teachers, in relation to the implementation of CCSS and in a more general sense, how their agency and voice has been impacted by the standards and reform movement of the last 20 years:

1) Tools, not Rules: Teachers who see it as their professional responsibility to negotiate students' interests with the demands of institution, discipline, community, and state regard CCSS as tools to use, not necessarily rules to obey. Alignment with state standards may be a goal for them, but this is not a given.

2) Time for Collegial Support and Collaboration: Teachers seek the time to engage in "true learning" with each other; they often find evaluation, information, and guidance from non-teachers to be irrelevant to their professional development. Unreasonable demands upon time, such as those that come from large class sizes, impinge upon time they could use for collaborative planning.

3) Shutting the Door? Teachers are conflicted about their relationship with the world outside their classrooms and its impact on those classrooms. Feeling their profession is in danger, when reform is irrelevant to their work, they often feel they must "shut the door" to that outside world in order to focus on their professional responsibilities.

In the sections below, I discuss each of these three frames and provide illustrative examples from the interviews and focus group. I also make reference to related literature that deepens the discussion of each of the three main frames for analyzing the teachers' perspectives on professional autonomy and voice. 
Frame 1. Tools, not Rules: Teachers who see it as their professional responsibility to negotiate students' interests with the demands of institution, discipline, community, and state regard CCSS as tools to use, not necessarily rules to obey. Alignment with state standards may be a goal for them, but this is not a given.

When school reforms are implemented, those who are directing or assessing the quality of that implementation usually ask questions about a teacher's "alignment" with or "fidelity" to new policies, materials, and programs (Protheroe, 2008). The former implies that the teacher has directed his or her professional activity based upon the new policy, but the latter might just as well be the result of a new policy matching what a teacher was already doing. Gaps between implementers' and practitioners' frames, regarding the role of a new policy in relation to practitioners' professional responsibilities, can lead to variations in outcomes, which will not make sense unless we understand what frames are operational for whom. For this reason, preliminary questions in interviews and the focus group about the purposes and significance of teaching were meant to reveal operational frames guiding teachers' behavior every day.

Teaching as Relation. What emerged as paramount for the teachers interviewed was the desire to meet students' needs in ways that are necessarily informed and influenced by relationship - a process where the transfer of information seemed in some ways secondary. For Abdulhadi Kaddoura, a math teacher, his desire to teach began when he realized he had something to give other people; he could "make connection." Pointing 
out that the role of the teacher involves so many responsibilities to so many different parties, and that parents, colleagues, and administrators all have different expectations, Abdulhadi argues for the role of the teacher as promoting human potential and change: "We are here to motivate, to encourage...We are here to give them hope." For English teacher Liane Strub, "what really matters... is each individual... the most rewarding thing about teaching is ... when you feel you have had a true connection to another human being, who just happens to be 16 or 17." Describing his principal reason for teaching, Jerry Brodkey, who teaches math, used a frame commonly used by these teachers to characterize their work, teaching as a privilege:

When the classroom doors shut, and I'm alone with 30 people, I have a unique opportunity that not many people in the world have, and that is to be with each other, in a kind of an intense learning environment, creating a safe environment, a trusting environment - and that, to me, is the beauty of teaching.

Jerry's description of teaching as, to some extent, world-creating, is something he and others referenced often, as they elaborated on the obligation to create an environment where students would feel safe enough to make mistakes. Liane appreciates "that opportunity to feel empathy and to listen and the opportunity to bring that child into the world that I am trying to create." Julie Marten, a social studies and art teacher, loves "getting to that point where everybody can talk about things. Where they start to feel safe and comfortable that their ideas aren't stupid. They're not stupid just because they don't know about a bunch of things." As Abdulhadi notes, "We have to care for these kids," 
and Liane reflects upon the trust you build as the reason "you feel - OK, what I do is important, and it matters that I do this every day," we hear how they perceive their job in psychological and emotional terms. But what comes through as they continue to talk about their work is the extent to which experience has taught them how central trust is to effective pedagogy. If information is to be transferred, instructions given, and structures adopted, students must feel safe enough to make mistakes, care about what's being offered to them, and be receptive to how it is offered. Teaching and learning are ultimately conceived of by these teachers as parts of a necessarily complex, human dynamic, where the need "to connect" is genuine response, pedagogical tactic, and professional obligation all at once (Dewey, 1916; Freire, 1970).

As veteran teachers experienced with teaching through successive waves of standards-based reforms, these teachers used frames for teaching that were substantially broader than what is covered by standards, which focus on the academic and evaluative even when discipline-specific work was discussed. Along with relationships, Anne Akey's passion for teaching is grounded in subject matter knowledge, but also implies the pleasure in helping students connect with that passion. "I like the bugs! I like the plants. And I really think everyone should know something about climate change and some of these issues, because they're the people who are going to go out and vote." Liane Strub speaks of her passion about literature to involve us in the important questions about what it means to be human, and Jerry discusses the need for teachers to help students reach 
understandings of themselves and others, which could never be reached strictly through technology. In the focus group, Abdulhadi highlights, to general agreement, the role of critical thinking, "I tell the kids, 'You're going to forget the algebra, you're going to forget the rules and the theorems, but we don't want you to forget to think."'

What these responses share is the notion that teachers must be fully present - that much of what goes on in a classroom involves a teacher's use of materials in order to guide students - and that the personalization of this process keeps veteran teachers engaged with their students and contributes to their sense of professional autonomy and satisfaction. "They look up to us to become better citizens," says Abdulhadi. "If I don't feel the math, I don't think I can teach it... it has to come from the heart and you have to be open with students. Open in every aspect." We all have memories of great teachers who provided us with this kind of example and guidance, and an instance of this was revealed even during this research. I had not known, until I was interviewing him, that Alan Eaton had been Jerry Brodkey’s student. I subsequently learned how much Jerry had been a model for Alan, academically and personally:

He was just such a human teacher for us... He very much wanted us to learn and to choose our way. He valued us, and so... when it was my turn to be a teacher, he was one of the people who stood out as a model, and more for his strength of character and self-discipline than in any single technique or event that he did - he was just a really good person that I hoped to be, and to be for my students - because I felt lucky to have him as a part of my young life. 
While standards do not purport to concern themselves with these aspects of teaching, proponents of CCSS would certainly claim that they in no way inhibit them. Yet, when Julie Marten tells us that what makes teaching effective is "not something that can be packaged -- it's about individual relationships," she makes a veiled stab at standards. Abdulhadi cites his first obligation to his students as to be "honest," explaining that he can only teach what he feels students need, and Alan Eaton complains that if he is expected by administrators at school or district levels to move down a checklist with curricula or lessons, then he will lose "authenticity." For him, there is more at stake than just the flow of a lesson, as teachers are "diminished" when they do not take responsibility for what they communicate and require. "It is crippling as a teacher," he says, "to not be able to ...vouch for the authenticity of the lesson. That's not a teacher, that's something else..."

CCSS and Standards-based Teaching. With the exception of Alan Eaton, a Latin teacher whose teaching is far less restrained by expectations of fidelity to standards (although there are California State Standards used for Latin) most of the teachers were not opposed to the standardization of concrete learning objectives at some level external to the classroom, and several were quite positive about CCSS in particular. English teacher Justine Rutigliano's enthusiasm for CCSS, in fact, seemed unqualified: “Common Core allows you to fold in a lot of different pieces, so there's a lot of real-life stuff in there - so, for example, articles, things that are happening in real life - politics, things 
that are happening currently in the real world." Although she acknowledged that these were aspects of the International Baccalaureate (IB) pedagogy she was already employing, she appreciated that CCSS seemed to be following the lead of IB and the Advanced Placement Language and Composition courses, both of which have emphasized complexity of purpose and audience, as well as the use of English within practical contexts, rather than the literary analysis, which has formed the core of English teaching in the past. She was also comfortable determining students' needs based upon the assessment tools developed by Smarter Balance, the testing company California has contracted for this purpose. "You start with the assessments," says Rutigliano of CCSS. "Teachers have to take them, talk about them, deconstruct them, so that we can understand what they are... and then you just go backward - backward planning, backward mapping." As she is the CCSS coordinator for the IB program at Sequoia High School, we might expect Rutigliano's methodology to align with the implementation goals of CCSS designers, state, and district authorities - that is, teacher-fidelity. She is confident that CCSS assessments will accurately reflect what students have learned, and she is comfortable with CCSS defining exactly what students should learn.

While there are still no CCSS directives in Anne Akey's subject, science, she was excited by the new Next Generation Science Standards (California NGSS, 2015), which she guessed would shape a future version of CCSS in science. She sees things heading in a good direction. "I do like the standards," she said, speaking of both the current national 
standards in science and the ones to come . When there are good standards and good tests, that's a lot easier to take than what we have been through recently." Her complaints were not with the previous standards, but with the district's use of them. While she did not find that the California State Standards for science were as good as the national standards, which she found "visionary," they were not the problem. Despite their not being adopted in California, she credited the national standards with helping her orient her own teaching and the teaching of science, nation-wide, towards "minds-on" inquiry and problem-solving, rather than just content-absorption and rote, hands-on (uncritical) laboratory experiments. She has been following the work on the Next Generation Science Standards and anticipates that they will go even further in this direction, focusing on fewer, bigger ideas (which, in addition to the critical thinking and problem-solving, would indeed be consistent with CCSS standards in Math and Language Arts) and on the earth and climate sciences she feels need more attention.

While Liane Strub, English teacher, and Julie Marten, social studies and art teacher, had specific criticisms of standards, both made it a point to say that they supported the idea of standards, in general, and had worked with them successfully in the past. Liane's original buy-in, she explained, was before the adoption of California State Standards. She and Anne had both been a part of generating district-wide standards over fifteen years ago. She found that process helped her teaching and increased the extent to which she used the standards as a guide - they applied to her class, they responded to the 
students' needs she perceived, and she was familiar with them and invested in the process from the start. She also considered the collaborative problem-solving with other teachers to be enormously valuable, professionally - a great time to share best practices and diverse perspectives.

Liane's assessment of CCSS was not as generous. Referring to the new emphasis on non-fiction texts, which represents a shift away from literature for much of the high school English curriculum, she derided CCSS's "utilitarian" emphasis, stating that, "tossing out all literary analysis is dangerous and unfortunate." While this does identify a trend in CCSS, it struck me as an overstatement regarding expectations. A graphic posted on the SUHSD website, adapted from SMCOE, cites the new ratios of non-fiction texts (which include texts in other disciplines) to fiction texts as 75 to 25 in high school (Sequoia Union, 2015). At WHS, I am still teaching works of fiction and that seems to be the normative expectation, although there has been significant movement in the directions that Justine Rutigliano celebrated - towards identifying a much wider range of purposes, audiences, and real-world contexts. This is consistent with the Advanced Placement English Language teaching I was already doing, and which I always felt was appropriate for all students, and so I am comfortable with the general direction of CCSS, in this regard, as long as the 75/25 ratio is enacted as intended, over all the disciplines. I do, however, share a frustration that Liane expressed in the focus group, regarding her department's lack of engagement with literature for aesthetic and philosophical purposes; 
Liane attributes that to CCSS, but I experienced that from the start of my career in public education, ten years ago. Overall, Liane is comfortable with CCSS objectives, but cannot always understand them. She consults them every night as she plans lessons, but she often ends up more confused than clearly directed - and the core value of the activity is sometimes lost on her:

I find I'm searching for the language that fits my pre-determined objective rather than being guided by the standards to plan my lesson. It reminds me a lot of my high school days, when I would write a research paper and then go back and produce the outline. My mind doesn't work in the way the standards dictate.

Liane found it absurd to expect a teacher to explicitly teach a standard. "It's so limiting," she says. "I can't believe that is a goal." Teaching, for her, is more organic, fluid, and complex. Multiple standards should be touched on every day - they cannot be used to structure a lesson. As with Anne, these objections may have more to do with administrative expectations of how a standard is taught, than with the standards themselves.

Julie Marten's positive experiences with standards were more conceptual - she had known them as a student abroad, and she sent her children to a French American school based upon the French system. She described the entire social studies department, during her years there, as resistant to standards that were clearly, in their opinion, "not written by teachers." They omitted information she thought generally recognized as essential by teachers (such as the experience of Native Americans in U.S. history) and 
were far too extensive for full coverage in other areas. As an art teacher, Julie found standards to be an "annoyance" rather than an obstruction. While she would trot them out when necessary to meet administrative requirements, she determined that, on the whole, she had "no choice but to dismiss them or else my students would be deprived of developing their skills in a broad array of mediums and expressive modes."

Negotiated Alignment. "We like the standards," says Abdulhadi, at the focus group, without being challenged openly. "I think the Common Core movement is going to generate some pretty interesting material," says Jerry. For both of these teachers, there is alignment between the CCSS and their teaching. They both, for example, put a high premium on the development of critical thinking and, in Abdulhadi's words, increased "problem-solving, more group activities, more discovery-type" learning. All of those emphases align with CCSS. Abdulhai has observed that the new Smarter Balance questions are more "active" for students, requiring them to reason and account for the steps they take to solve problems. "I've always thought," reports Jerry, "that I've had a sort of Common Core approach." Indeed, as he describes his class, it does sound fully aligned with the stated goals of CCSS:

I say in my math classroom that I want as much discussion as you get in your English class. I want to know as much about how you are thinking problems - I'm not worried as much about the right answers - I could give you all the right answers to the problems. What I'm interested in is the approach to the problems... [I have] little emphasis on memorization... we do a lot of writing... kind of this meta-analysis of problem-solving, learning that is bigger than, 'you factor a quadratic equation by doing a recipe.' 
While Abdulhadi states, "You have to have the standards - guidelines," he is also clear that they are tools for him, not rules he worries about following. He says that he might be teaching different material in different classes, even though both classes are the same subject and level. Every year, depending upon his students, he re-evaluates the standards, just as he does his textbooks, technology, problem-focused instruction, etc. for potential adaptation to better meet the particular challenges he is facing. While he approves of CCSS, his use of them suggests that his primary fidelity is to the welfare of his students:

Your experience from previous years tells you there's something not there... Or there's something the standard doesn't fit - it's not right. You throw it out. There are some things I emphasize and some things I skip totally... It's not about what the school wants, or the district, it's about what I think the kids need to enable them to do well next year - what are the skills they need.

Alignment with standards may be a goal for Abdulhadi, albeit a secondary one, but for Jerry it is merely a happy accident that the standards align with his teaching. "Whenever I hear the word 'standards' my eyes kind of glaze over... They haven't influenced my teaching," he admits in the focus group. He further critiques the intent of standardization by suggesting that CCSS are unlikely to create identical experiences in different classrooms. Furthermore, if teachers are referencing as many sources as they should for guidance and bringing their own perspectives and passions to bear, then 
everyone's class should not be identical. "I'm not sure by having the standards that we've eliminated the differences," he argues, "and I don't know that we want to."

Because, for most of these teachers, the most compelling frame for professional responsibility is that of helping students, alignment with standards becomes something of a two-way street. Teachers will use standards as guides, to the extent that those standards align with the work they think they need to do. This negotiation is described by Julie Marten in a larger sense as one between external expectations and personal judgment, which, over time, leads to a higher level of professionalism - a practical wisdom that enables her to effectively meet students' needs:

No one tells you it will take you many years to develop your craft, and that you know your craft is almost there when you can tell the difference between problems that can be ameliorated by becoming a better teacher and problems that are institutionalized and must be accepted... I have my own style and approach ... and have learned to nod towards most professional development but not feel obligated to take on any of their bottled generalizations, which generally clash with my craft.

In summary, four of the teachers I interviewed recognized a need for state standards. The exceptions were Alan, Jerry, and Julie, all of whom felt that a teacher's sense of what to teach should come from larger conversations and experiences within the discipline, with colleagues, and with professionals in the field. That said, Julie was not opposed to standards, per se, as long as they were devised by teachers, and Jerry believed that CCSS promote beneficial standards, with the potential to guide teachers in the same ways that he teaches in his classroom. In total, four of the teachers I interviewed were 
positive regarding CCSS. Justine was optimistic about CCSS in every respect. Jerry, Abdulhadi, and Anne all expressed guarded optimism about CCSS, depending upon how they were implemented. Liane expressed reservations about CCSS themselves. Julie, who was critical of the California State Standards, has not had experience with CCSS - just as Alan has not. Julie was, however, critical of teachers' relative exclusion from the development of CCSS (Schneider, 2015).

\section{Frame 2: Time for Collegial Support and Collaboration}

Teachers seek the time to engage in "true learning" with each other; they often find evaluation, information, and guidance from non-teachers to be irrelevant to their professional development. Unreasonable demands upon time, such as those that come from large class sizes, impinge upon time they could use for collaborative planning.

Almost every teacher interviewed at some point asserted that more could be learned from working with other teachers than with instructional coaches or outside consultants. "Seeing teachers in action is also amazingly powerful," Liane added to that sentiment. Anne missed the unstructured, collaborative professional development time she said was more common in the district ten or fifteen years earlier. Speaking about the same teacher-collaboration that engaged Liane with standards in the late 1990s, she mused, "What those standards are, we probably don't even remember anymore. But that 
was some of the best time I've had in the district... that was fifteen years ago. I haven't had those type of experiences more recently."

The unanimous desire to work with colleagues involved a number of factors, most importantly the belief that only teachers understand the problems teachers face everyday, partly because they are actively involved in solving them. There seemed also to be skepticism about any problem-solving that is overly abstracted and delivered by experts from the outside. Abdulhadi told a story that all the teachers seemed to relate with: a day wasted for an entire department, classes left with substitutes so that teachers might be delivered a poorly designed and taught lesson, irrelevant to their work, by an outside consultant. Asked about what kind of professional development she would like, Julie responded clearly: "Definitely working with other teachers in our district. In 13 years I have never had any other type of staff development be useful."

For most, one reason to work with colleagues was out of recognition for the diversity and depth of those colleagues' expertise. In the spirit of Elmore's (2008) suggestion for tapping faculty expertise through distributed leadership, Jerry says, "I look around the staff room - incredible people. Let them be free to innovate. Give us time to do true learning from each other." Perhaps standards might be one of the tools teachers use to arrive at quality teaching, but for Jerry, teaching and real accountability are too important and complex to be reduced to fidelity to standards. "The true value," he says, "comes when I sit down with the other two people teaching Calculus, and we say, "What 
are your students struggling with? How do we approach this topic?'... We're professionals."

The teachers not only wanted to learn from their colleagues, they wanted to be assessed by them, too. All agreed that only a teacher could adequately understand the complexities of the classroom, and all expressed disdain for being evaluated by an administrator who had no experience in the discipline he or she was evaluating. Alan suggested that administrators teach a single class. Jerry claimed that true "accountability" could only be achieved if administrators become deeply familiar with the work going on in classrooms. Embedded in his hoped-for scenario are reference points for a teacher that suggest professionalism should involve discipline-work far deeper than just working your way down a standards-based checklist:

...The students hold me accountable, and the parents hold me accountable, and the administration should hold me accountable, that they can come into my classroom at any time... What I've been waiting for my whole career was a principal to say, "We're not going to talk about tests; we're not going to talk about standards." I'm going to call Liane in... and I'm going to stop by her classroom... I'm going to call Alan in and say, "Alan, how are you approaching Latin this year? ... Have you talked about it with peers and colleagues? Are you looking at information from a national academy...?" And then I, as a principal, am going to be accountable to the board, and to the community, and to the superintendent in making sure that every student in every classroom has a quality experience every day.

With more time, Julie suggested, teachers could have "think sessions," where they might engage intellectually and move forward in open-ended ways. Collaborative time, she believed, need not always be project- or curriculum-driven. Smaller student loads, 
according to Julie, could give teachers more time for students and for working with colleagues "brainstorming, thinking, and sharing what's working and what's not working in the classroom."

Virtually all of the teachers' complaints about SUHSD professional development referenced activities over the past ten or fifteen years. In fact, quite a bit has changed very recently, and Liane noted with approval how much SUHSD professional development has been heading in all the directions found above, on teachers' wish-lists - the distributed expertise model (Elmore, 2008), observing other teachers, and collaboration. At all the SUHSD sites, the "cohort model" (Appendix B) is being piloted by teams of teachers, with the support and guidance of the district's professional development department. Teachers can arrange for release time to follow the following six steps: 1) Form a small group of teacher-colleagues from the same discipline; 2) attend professional development training for group collaboration; 3) develop observation protocols and observe teaching at other sites; 4) observe peers and engage in lesson study; 5) strategize and implement lessons, collecting student work, 6) analyze student work and create new steps for instruction. Liane expressed "high hopes" for this model of collaboration and observation, adding that she would also "like the opportunity to collaborate with my colleagues in other disciplines (science and social studies, in particular) to develop units that weave reading and writing across disciplines." Justine was also enthusiastic about the steps SUHSD was taking to implement CCSS. As a 
CCSS curriculum coordinator at SHS, she reported that teachers there were being given the time and flexibility they needed to adapt and collaborate.

But Alan is not convinced that there needs to be a professional development department at all. When asked what he would do, if he were given the job of leading professional development at the county level, he said:

My first act would be to eradicate the professional development department at Sequoia Union High School District. Every single person on that staff would be assigned back to teaching. All professional development within the district would again devolve to the teachers themselves, and the topics that would be chosen for teacher development would again roll back to teachers... Simplify life for all teachers, and then I make the system itself more efficient.

As will be seen below, Alan considers meta-teaching about teaching to be superfluous to genuine teaching and learning. His skepticism here complements Jerry's notions of standards as needless "overlay," and all the "noise" of school reform. "Do what Alan says," Jerry recommends. "Eliminate all this extra stuff, and say, 'Your job this year, instead of going to district meetings - instead of doing this - I want you to observe ten teachers and have conversations with them about what you saw." He would also have ten other teachers observe and discuss the teacher. After that, the role of administrators should be to stay out of the way. "We'll buffer you as much as possible from all the nonsense in the environment," Jerry's imaginary administrator assures him.

\section{Frame 3: Shutting the Door?}


Teachers are conflicted about their relationship with the world outside their classrooms and its impact on those classrooms. Feeling their profession is in danger, when reform is irrelevant to their work, they often feel they must "shut the door" to that outside world in order to focus on their professional responsibilities.

The image of the shut door repeated, particularly during the focus group. Although first offered by Anne in celebration of something she loved about teaching, the "freedom when [she] shut[s] that classroom door" reveals itself as also a strategy, when Jerry begins his explanation of the beauty of teaching with the phrase, "When I shut that classroom door..." The shut door became a common reference point during the focus group discussion - a proxy for the intrusion of reformers from outside the school, administrators within it, popular culture, and technology. These were not teachers who were opposed to accountability, change, or engagement with the larger world, per se. And there was tension within the group in terms how much that door should be closed. Some welcomed opportunities to engage with the world through the lenses of their disciplines. But the closed door, or the turning off of the "noise" of irrelevant demands or unwarranted intrusions, became a theme returned to often as a key factor in distracting the teachers from sustained engagement with their students and pedagogical innovation.

Alan, perhaps characteristically for a teacher of Latin, which has endured for centuries, stated the need for shutting the door the most emphatically. "We are not the outside world," he declares, in response to my assertion that our job was to negotiate 
students' interests with those of the outside world. "We are school. And a school - its work is other things." In his interview, it is clear that he is not being fearful, intransigent, or narrow. His claim is that teaching and learning require a scholarship and passion, which must be discovered along the well-worn paths provided by disciplines. He is concerned that clear lines are blurred, challenges compromised, and history cut down to the present when popular culture and standards simplify what is necessarily complex. In a way that is perhaps unthinkable for a teacher in earlier grades, Alan sees himself as introducing new learners to his discipline through teacher-guided, personal discovery. This is something he believes cannot be mass-produced for a generic student: ... standards as they currently appear are not what guides teaching in many cases because... for the students to really benefit, it has to be more than that... Someone who studied English or history, they have a specific passion, they have a certain depth of field and they have knowledge of content that is unmatched by anyone who studies education... [which is] a complete distraction from learning actual things, and a cultivation of administrivia and meta-thinking that can't be applied anywhere outside of its own perpetuation.

Testing. Most of the teachers' apprehensions regarding CCSS, however, focused on testing. Recalling how the entire science program at WHS constricted with the introduction of high-stakes STAR testing, a component of No Child Left Behind (NCLB), national legislation paired with the development of the first set of California State Standards, Anne Akey reminds us that she is not necessarily opposed to standards that she has seen them work when correctly implemented. But she reports: 
STAR was not a good experience here. It really limited what we did: it got rid of some of our best programs, and best ideas... the focus on this very broad body of knowledge, tested with multiple-choice questions - as opposed to doing science, as opposed to understanding science.

Anne repeats, at the focus group, that she likes standards because they are guidelines, not curricula. She clarifies that they leave her with choices to make about how she teaches. On the other hand, she notes the challenges of the district's use of assessments as impeding her instruction and autonomy.

Much more restrictive is what the district is doing. The benchmark exams... with no regard for the individual teachers and their emphases... I find the district much more restrictive than I do the standards themselves.

Note that Anne's objection to the testing is not that her own teaching will be assessed based upon those scores. Abdulhadi did express some exasperation with the fact that 'It's all going to come down to testing. That's what's going to determine if you're a good teacher or not... how the kids 'perform.' Because they don't know what's happening in the classroom. They only know... what the numbers say." But this was more a critique of reformers' notions of accountability than anxiety about job security. Akey's concerns are that the focus on testing compromises the educational experience, and forces compliance in ways that limit teachers' autonomy and sense of professional judgment. This sentiment was echoed by most of the teachers. Liane is "dismayed by the erosion of autonomy teachers have experienced since the implementation of NCLB." According to Abdulhadi, the benchmark testing Anne referred to fragmented material and led to the over-proscription of curricula. Sometimes, this occurred at the department- 
level, as teachers "deconstructed" standards in order to meet benchmarked requirements. Although CCSS now are less detailed and over-loaded than the original California State Standards, Abdulhadi is worried about the same thing happening, as the standards are divided and apportioned until they become just as restrictive and burdensome as previous standards were. As pressure mounted "over the years," Abdulhadi noted, "I found myself teaching, not what I want, but rather to the test - and that's not what teaching's all about." Nor does Abdulhadi believe that a standardized test can quantify what a teacher does, because the effects might not be seen for a year or two, and students' capacities change as they grow.

Jerry's concerns about CCSS as a whole are also triggered by the same emphasis on testing he witnessed during NCLB implementation. One of his concerns is that testing becomes an obstacle rather than a vehicle for real improvement. "If CCSS manifests itself as a top-down curriculum with demands and pacing guides and standardized testing," he warns, "then teachers will find a way to get around it and it won't really change the quality of what happens in a classroom." His ideas about teacher-change are from observation, experience, and his doctoral work (Brodkey, 1986). "I think change is harder than that. It might mean working intensely one-on-one... or collaborating... working with mentor teachers - some of the really hard work." Whereas, if you apply enough pressure, he believes, teachers will probably get test numbers up without this being indicative of any actual learning. This, Jerry implies, is because people who do not teach 
do not understand the difference between what shows up on a test and what is learned and students will suffer for that. Standardized assessments are blunt instruments and Jerry's hopes for a "truer reform" would involve recognition of a variety of teaching strategies, autonomous but accountable teachers, and lots of time to try and evaluate new approaches, new technology, and the best of what is already being done. The "stew" will take years to "really simmer" until we know what we have, he says. "That the accountability component is being impressed upon it very quickly" makes him skeptical.

As noted earlier, Justine Rutigliano's attitude towards the CCSS testing was uncomplicated by the reservations shared by the other teachers. She was, in fact, comfortable with test results constituting as much as $50 \%$ of the assessment of her work. She was impressed, when administering a Smarter Balance practice test, by the questions and the tasks, which she saw as promoting critical thinking and equity. She finds that, because all teachers everywhere must read the same directions, including the presentation of materials, the test itself might compensate for a bad teacher (at least during the test). She also finds that the questions do ask for higher-level, critical thinking than she has seen before on standardized tests:

You know, the rigor, you know — ramp it up... it was interesting — they were talking about, you know, it wasn't so explicitly mentioned, but they were talking about authorial purpose, intended audience, and those are things that kids need to know, you have to be aware... And then they went in and they did some computerized exam... they were supposed to be using some of the information that they learned in that session. So I think that's kind of cool. Whether you have a terrible teacher, someone who is 
not familiar at all with poetry, if you read through the script, at least the kids can get a general idea.

Justine, it would seem, does not share the anxieties about CCSS or standardsbased and accountability reform that were evident in the other interviews and during the focus group. As she did not participate in the focus group it is hard to tell if she would have offered a dissenting voice when those concerns arose. Perhaps, as Anne had done, she might have modulated the concerns by pointing out what was reassuring or where important distinctions should be made (for Anne, it was between the standards themselves and the district's implementation of them).

For Liane Strub, the same tests that impressed Justine were a source of heightened concern. She was also involved in the same Smarter Balance practice session, but at another site. Despite CCSS's "lofty aspirations," she wonders, do they really test for critical thinking? She's all for that, she says, "but the test isn't aligned for that. I'm telling you it's not." According to her, the analysis of text, calling for close reading skills, was merely looking for certain key words. "That's not critical thinking!" she protests. "That's regurgitation. It's just different regurgitation than multiple choice. So the test is wrong-headed." As for claims that CCSS and its tests will ensure greater equity, she was equally skeptical:

My god, are you kidding me? I mean, what creates equity is human -- it's not written. It's person-to-person. What creates equity is if teachers all buy into the idea that all students - and not as a slogan! - but that all students can learn, and that having high expectations for every student in front of you - that is going to do more to bring that student up to some 
kind of standard level of education than an explicit statement of what that student should know at the end of eighth grade.

Edu-business. Underneath teachers' skepticism about testing lies deeper anxiety about the standards and accountability movement itself. Teachers' concerns echoed Ravitch's critique of current reform as a push for the privatization of public education, with fears further fed by exclusion from CCSS development. Julie Marten suggested that, "if the USA is committed to hav[ing] a functional standardized education... we might as well do it properly by having it guided by experienced classroom teachers rather than academics, politicians, and edu-business."

Expressing skepticism about what "the people on top - up there--" want (money), Abdulhadi tells a story about a presentation for parents at the school his daughter attends. It was about CCSS, but he was not invited to present. Instead, engineers who helped make CCSS tests told parents what CCSS were all about, including how they would be used in the classroom. Test-makers and book publishers, Abdulhadi elaborates, stand to profit when reforms like this kick in. Marten adds to this, "In the last two decades, people at the level of capital realized, 'Oh, there's this whole area that we've ignored, where there's an enormous amount of profit to be made from... I can't believe we've completely ignored this pocket - a 30 billion dollar industry!"”

Abdulhadi's concerns about CCSS reflect his priorities: integrity, commitment, and pedagogy. "As a teacher," he says, "I would hope that anything we teach would be something lasting. The kids would take it into their lives..." The CCSS themselves have 
a great deal to offer, he admits - in particular the emphasis on problem-solving. But he wonders if the standards and accountability movement, or new powers that be or are to come, will follow a familiar pattern:

I'm afraid that's going to be something like other buzz things we've had in the past -- every five, six years, we're going to have something new... Oh! This CCSS is not working, Oh! We have this international way now... whatever... and then you're going to find new books, new curriculum, new tests. New everything -- and then, what about what we've worked on well, that's history...That will be my biggest fear... it's something being driven by something else out there -- not teachers. Maybe politicians, business people, companies, making billions of dollars from these books... So I hope this will work and we will stick to it and if it doesn't work we can improve on it instead of just to revamp and then create all over again. As a teacher, that's not good -- to do something for just four five years and then... if it's not working, take what's not working and fix it, but you don't throw everything away and start all over again.

The shut door metaphor referenced throughout the evening appeared to reveal underlying issues of trust. On one level, the shut door was a strategic reaction to the lack of trust teachers felt that policymakers and others outside the classroom had in their ability to do their jobs, as these teachers perceived reform policies stressing testing and accountability as increasingly intrusive and directive. These policies frame educational problems in terms of teachers' work, rather than the conditions teachers and students deal with everyday. The consequent misalignment, between how teachers and reform policies frame secondary education's most pressing problems, decreased these teachers' trust of a world they felt was losing trust in them. As their insecurity increases, the door becomes a 
way to reduce variables to those that are known and trusted as relevant to the problems posed by students and curricula.

While the statements about the shut door were uttered without tension in the early part of the focus group, tensions arose later in the evening when the group was discussing the divide which the door image represented, between the classroom world and the world outside, from which emanate administrative demands, new reforms, and technological and cultural challenges. After voicing skepticism about the motives of many reformers from the business world, and the power they had to change things, the group discussed their own possible obsolescence, with some reformers pushing forms of education that might change the role of the teacher to that of technical supporter. This set up an escalation of tension, as the group returned to the question of the role of the teacher, in negotiating influences from outside the classroom. This was one of two points in the evening when I put forth my own point of view strongly - both in reaction to the shut door metaphor. Later, I would make a case for teachers coming out of isolation, coalescing to take control over their own profession. At this time I put forth my Deweyan notions of the educator as a negotiator between students' individual needs and the demands of institution, discipline, and culture.

Alan protested, "We are not the outside world." Heads nodded, while others maintained that the influence of technology was inevitable and not necessarily negative. A climax in the discussion occurred as tensions within the group combined with 
generalized tensions, which had arisen while discussing the big business of school reform. Alan finally reduced the tension with an eloquent plea for recognition of that which cannot be made obsolescent: scholarship, human guidance, and patient discovery, within a discipline. "Before standards," he said, "Latin teachers have been around for about 3000 years. They have survived the Christians, and they have survived the capitalists, and I think they will survive the Common Core, as well. It's just -- a blink of an eye. It will pass." In this way, the narrative construct of the evening revealed the most salient concern for teachers. Insecurities arose when the discussion was about matters beyond teachers' control, and the power players who seem to these teachers to be endangering the public system. The loss would not only be to their livelihoods, but to something to which they had dedicated their professional lives, motivated by notions of the goodness of that work in this system (Lightfoot, 1983). The only moment of disagreement in the evening was this one - a question of how much we should allow reforms, cultural changes, and administrative requirements to affect anything we do. My proposal for a middle ground proved far more controversial than I had thought it would. But as a veteran teacher, I too was attracted to the poetry of Alan's response to me and reassured by the notion that teaching was a timeless human activity, always needed and bound to endure. 


\section{Conclusions and Implications}

\section{Professional Autonomy and Expertise}

While any of the three frames above could lead a teacher to resist CCSS implementation, it is worth noting that all of them, as expressed by these teachers, are rooted in the professional desire to serve students' needs as effectively as possible.

Despite some skepticism about how CCSS might be implemented, based upon the NCLB years, or even with standards themselves, these teachers, as a group, were not resistant to change or external authority - and certainly not to accountability. This is in contradistinction to the frames commonly used, both culturally and in reform discourse, to characterize teachers' resistance to new reforms as unprofessional, with motives attributed to teachers such as laziness, idiosyncrasy, and the fear of innovation (McGill, 2015; Ravitch, 2013). This was not a group of disgruntled teachers. Objections, when there were any, were expressed in terms of pedagogy. There were only a few objections to CCSS themselves, and while there were some concerns expressed about how CCSS might end up being implemented, there were few complaints about how implementation was being handled by SUHSD. The math teachers were very supportive of the kinds of learning that CCSS prioritize, although they made it clear that this was more a matter of the standards aligning with their teaching, rather than the other way around. One English teacher was enthusiastic about all aspects of CCSS, the other not sure yet about the 
standards themselves. Reactions to the California State Standards preceding CCSS were not generally positive, so change was welcome from virtually all the teachers. Attitudes about standards to come, from the teachers whose subjects were not yet covered by CCSS, were very mixed. One was very optimistic; one was supportive of standards in general, but critical of how they were being devised; and the third was dismissive of state standards in general, out of a deeper commitment to the subject matter itself.

Most of the anxieties expressed were about testing. The primary fear was that it would become the focal point for curriculum decisions and administrative energy, as it was during No Child Left Behind (NCLB) implementation, followed by the concern that it would be used to assess what it could not effectively assess, such as teacher-quality and critical thinking. Contrary to another popular framing of teachers' resistance to some reforms, as an avoidance of accountability (McGill, 2015; Ravitch 2013), these teachers were clear in their interviews and in the focus group that they took accountability to students, parents, school, community, and discipline very seriously - that professionalism was not possible without it. Some of the fears about testing were part of a larger fear that public school teaching itself was in danger, from billionaires and policy makers who are subverting public schools to serve their own commercial, political, or ideological interests.

When I coded for how the teachers were thinking about their own teaching, every teacher identified his/her responsibilities to students as primary, among an array of 
responsibilities to other parties, and almost every teacher referred to the professional satisfaction of relationship, honesty, and love for subject matter. These all imply an individual presence - a personality with authenticity, necessarily linked to authority which would be impossible for a teacher to realize if the intent were merely to meet institutional demands. When these teachers spoke of the freedom they felt when they "shut the door" or turned off the "noise" outside their classrooms, they were identifying the authority they needed to meet professional responsibilities to students. Requests for time, freedom, and trust were framed by an over-arching desire to create environments students need in order to learn.

\section{Going Forward with CCSS Implementation: Increasing Teachers' Participation}

The teachers interviewed like CCSS. The math teachers appreciate the new emphasis upon critical thinking, problem-solving, and communication about process - as opposed to a focus on memorization, formula, and product (National Governors, 2015). In English, Justine Rutigliano is impressed by the new emphasis on "real-world" skills, demands, and contexts for assignments. She also likes what she's seen of the assessments. All but one (Alan) said that CCSS have the potential to take teachers in positive directions. Liane uses them every night, when she plans lessons, although she admits that she often has to plan first and then find a place for the standards. Justine reports that her intention is to use standards-based assessments as her guide, planning 
backwards from test results. However, the question of professional self-determination remains critical for most of these veteran teachers. They hope for alignment between their practices and CCSS, but that depends, to some degree, upon how the district and school site administrators require them to enact the standards and the specifics of professional development support.

All of the teachers report a need for time and the desire to collaborate with peers. Most of them framed the professional development activities of the last fifteen years primarily workshops led by district or school-site administrators, or, worse, "experts" from outside the district - as time (and district money) wasted. There seemed to be exasperation with how others condescend to them, offering them formulas out of a failure to appreciate the instructional complexities of their work and their own teaching expertise. In the end, they had found the most value in observing and being observed by colleagues, with critical, supportive discussions to unpack what was going on and think creatively about how to improve. In regard to CCSS, the teachers wanted time to unpack and plan with colleagues with whom they might solve problems collaboratively. While the district is now offering this to teachers, it is something that must be arranged during release time, and these teachers thought it was essential that this be a regular part of their work-week.

The teachers' perspectives on CCSS conceptualization and elements point to important factors that my district and county can rely on for CCSS policies and 
professional development implementation. When policy objectives are re-framed (Coburn, 2006) to address the needs of students, rather than the deficiencies of teachers, then implementers become partners with teachers, and teachers will respond, in kind. To the extent that CCSS are framed as opportunity rather than obligation, teachers are more likely to respond with new energy and genuine improvement. What those opportunities are should be negotiated, as teachers are listened to and as both teachers and administrators unite around meeting students' needs. Perhaps the opportunity needed is for teachers to collaborate, or to create new curricula, or to rise to new forms of critical and inter-disciplinary pedagogy, contextualized by real-world experience. Once CCSS are re-framed as opportunity, the nature of that opportunity can become something genuinely responsive to need, determined in partnership. The teachers interviewed all expressed a deep interest in professional collaboration with peers, a key component for the district and county to feature in CCSS implementation.

The teachers' perspectives indicate that teachers' professionalism is enhanced when they participate at all levels in the reforms that shape the work they do. These veteran teachers, who have seen successive waves of standards-based reform over the last 20 years, are adamant that lasting reforms must include teachers at all levels of change. Research illustrating this can be found in the field of teacher-education, as schools of education have wrestled with newly assertive state policies. Two self-studies (Kornfeld, Grady, Marker \& Ruddell, 2007; Peck, Galluci \& Sloane, 2010) conducted by faculty in 
California programs contending with the intensely proscriptive State Senate Bill 2042 (Kornfeld, et al., 2007; Peck, et al., 2010). Both programs were at odds with the explicit requirements and implicit ideology expressed in the new legislation. But, whereas Kornfield's study details teachers' resistance to the legislation, Peck's (2010) self-study reports on an alternative approach, applying Wenger's (2000) ideas about professional learning communities, which are relevant to CCSS implementation at this time.

Wenger (2000) found that healthy and productive change occurs when a balance is struck between "reification" (the formalization of processes) and "participation" (the negotiation of changes occurring through social interactions). Although the teachers in Peck's study begin with the same objections to the same legislation as the teachers in Kornfeld, et al., the different approach yields both greater teacher-satisfaction and policy alignment. More than just making the best of a bad situation, opportunities were created for inquiry and program improvement, as recursive cycles of data collection were used to investigate how learning and change processes operated within the program, and how new regulations were affecting teachers and students (Peck, et al., 2010). Every step taken in Peck's program was inclusive. All faculty members collected data, shared expertise, and participated fully in the construction of programmatic inquiry and response to the legislation, conducted in multiple levels of small group work and collaborative strategic planning (Peck, et al., 2010). 
The balance between reification and participation described by Wegner is the best way to maximize frame alignment during CCSS implementation, as it professionalizes teachers, seeking their participation with reforms within the larger context of meeting students' needs critically and creatively. In the final paper in this collection, I propose a way to take concrete steps to strike the balance between reification and participation that Wenger (1998) offers as essential for learning to take place in professional communities. This involves the distribution, viewing, and use of the filmed focus group because, at its root, the intention is to create wide-ranging teacher-led discourse. Administrators must first agree that there is professional value in such discussions, and then concerns and new ideas might move more freely, both laterally and vertically, to increase teachers' participation in the policies that shape their work. The work currently going on in the SUHSD Professional Development department, such as the Cohort model discussed above, suggests that things are moving in very promising directions, modeling what other districts might replicate and adapt.

The interviews and the focus group allowed me to seek out dedicated, veteran colleagues to share experiences, thoughts, and perspectives on educational reform efforts over the last 20 years, and in particular to examine CCSS conceptualization and implementation. I was most interested in understanding how veteran teachers, with their wisdom of experience and expert subject matter knowledge, viewed CCSS in relation to their sense of themselves as professionals, and how they viewed their autonomy and 
agency as teachers. I found that my colleagues remain positive and grateful for the privilege of performing the work they love. They conceive of their work primarily as service, performed in the context of social and intellectual relationships with students. Because they have so many students and their energies are so directed to meeting the challenges posed by those students and the demands of their disciplines, I do not think these teachers have a great deal of time to address matters of policy; so even their thoughtful responses to my questions struck me as affected by the novelty of being asked. I think that is unfortunate, and that critical matters of educational policy continue to be decided by people who neither understand the needs of students nor the current difficulties and potentials of teaching, as well as these teachers do. When I taught in private schools, I felt that this situation was modulated to a certain extent by an attitude of deference many administrators seemed to have regarding teachers and the work they did in their classrooms. In the best case, this led to inclusion, with administrators seeking answers from classroom teachers, before creating policy. The hierarchical and largescale nature of public education, unfortunately, can sometimes have the reverse effect, with external authorities shaping policy and site administrators preoccupied with conformity. This demeans and excludes the professionals who are most qualified to identify problems and create the innovations that will improve educational experiences for students. In the third and final paper in this collection, I describe and discuss a 
promising new framework for CCSS implementation and professional development that foregrounds teacher autonomy and pedagogical wisdom. 


\section{References}

Bogdan, R. \& Biklen, S. (2007). Qualitative research for education: An introduction to theory and methods, $\left(5^{\text {th }}\right.$ ed.). Boston, MA: Pearson.

Brodkey, J. (1986). Learning while teaching: Self-assessment in the classroom (Unpublished doctoral dissertation). Stanford University, Stanford, California.

California Department of Education. (2015). Common core state standards. Retrieved at: http://www.cde.ca.gov/re/cc.

California Department of Education. (2015). NGSS for California Public Schools, K 12. Retrieved at: http://www.cde.ca.gov/pd/ca/sc/ngssstandards.asp

Cherry-McDaniel, M. (2014). Coming full circle: A young teacher's journey with the standards movement. English Journal, 104(2), 93 - 98.

Coburn, C. (2006), Framing the problem of reading instruction: Using frame analysis to uncover the micro-policies of policy implementation. American Educational Research Journal, 43(3), $343-379$.

Crowther, F., Ferguson, M., \& Hann, L., (2009). Developing teacher leaders, $\left(2^{\text {nd }}\right.$ ed.): How teacher leadership enhances school success. Thousand Oaks, CA: Corwin Press.

Cuban, L. (2013). Inside the black box of classroom practice: Change without reform in American education. Cambridge, MA: Harvard Education Press.

Deal, T. \& Peterson, K. (2009). Shaping school culture: Pitfalls, paradoxes, and 
promises. San Francisco, CA: Jossey-Bass.

Dewey, J. (1904). The relation of theory to practice in education. In The third yearbook of the National Society for the Scientific Study of Education: Part I: The relation of theory to practice in the education of teachers (pp. 9-30). Chicago, IL: University of Chicago Press.

Dewey, J. (1916). Democracy and education. New York, NY: Macmillan Company.

Elmore, R. (2008). School reform from the inside out. Cambridge, MA: Harvard Education Press.

Freire, P. (1970/2000). Pedagogy of the oppressed. New York, NY: Continuum.

Giroux, H. (1996). Slacking off: Border youth and postmodern education. in Giroux, H., Lankshear, C., McLaren, P., Peters, M. (Eds.). (1996) Counternarratives: Cultural studies and critical pedagogies in postmodern spaces (pp. $59-80)$. New York, NY: SUNY Press.

Goffman, E. (1974). Frame analysis: An essay on the organization of experience. Cambridge, MA: Harvard University Press.

Halverson, E. R. (2010). Film as identity exploration: A multimodal analysis of youthproduced films. Teachers College Record, 112(9), 2352-2378.

Hargreaves, A. \& Shirley, D. (2012). The global fourth way: The quest for educational excellence. USA: Corwin Press. 
Hulce, C., Hoehn, N., O'Day, J., \& Walcott, C. (2013). California and the common core state standards: Early steps, early opportunities. Washington, DC: American Institute for Research.

Kamberelis, G. \& Dimitriadis, G. (2008). Focus groups: Strategic articulations of pedagogy, politics, and inquiry. In Denzin, N. \& Lincoln, Y. (Ed.s). Collecting and interpreting qualitative materials. Los Angeles, A: Sage Press.

Kornfeld, J., Grady, K., Marker, P., \& Ruddell, M. (2007). Caught in the current: A selfstudy of state-mandated compliance in a teacher education program. Teachers College Record, 109(8), 1902-1930.

Lawrence-Lightfoot, S. (1983). The good high school: Portraits of character and culture. U.S.A.: Basic Books, Inc.

McGill, M. (2015). Race to the bottom; Corporate school reform and the future of public education. New York, NY: Teachers College Press.

The National Commission on Excellence in Education. (1983). A nation at risk: The imperative for educational reform. Retrieved at: http://www2.ed.gov/pubs/NatAtRisk/index.html.

National Governors Association Center for Best Practices and the Council of Chief State School Officers. (2015). Common Core State Standards Initiative. Retrieved at: http://www.corestandards.org/. 
Peck, C., Galluci, C., \& Sloane, T (2010). Negotiating implementation of high stakes performance assessment in teacher education: From compliance to inquiry. Journal of Teacher Education, 61(5), 451-463.

Phillips Exeter Academy. (2015). Harkness. Retrieved at: http://www.exeter.edu/admissions/109 1220.aspx.

Protheroe, N. (2008) The impact of fidelity of implementation in effective standardsbased instruction. Principal, September/October 38 - 41. Retrieved at: www.naesp.org

Ravitch, D. (2013). Reign of error. New York, NY: Knopf.

Saldana, J. (2013). The coding manual for qualitative researchers, $\left(2^{\text {nd }}\right.$ ed.) London: Sage Publications, Ltd.

Schneider, M. K. (2015). Common core dilemma: Who owns our schools? New York, NY: Teachers College Press.

Seidman, I. (2013). Interviewing as qualitative research, ( $4^{\text {th }}$ ed.). New York, NY: Teachers College Press.

Sequoia Union High School District. (2015). Core understanding I. Retrieved at: www.seq.org/+uploaded/file_1978.pdf.

Shulman, L. (1998). Theory, practice, and the education of professionals. In Shulman, L. (2004). The wisdom of practice: Essays on teaching, learning, and learning to teach (pp. 511 - 526). San Francisco, CA: Jossey-Bass. 
Wenger, E. (1998). Communities of practice: learning, meaning, and identity. New York: Cambridge University Press. 


\section{Proposal to San Mateo County Office of Education: Professional Development to Amplify Teachers' Voices During Common Core State Standards Implementation}

\section{Common Core State Standards (CCSS) Implementation}

This paper is the third in a collection addressing the impact of standards-based reform, and CCSS in particular, on teachers' perceptions of their roles. The first paper was a narrative inquiry, examining my own experiences teaching in independent and public schools, in relation to agency, voice, school cultures, educational policy, and pedagogy. The second paper analyzed data taken from interviews with seven teachers and a focus group with six of them. Following an agreement made in a consultancy partnership with San Mateo County Office of Education (SMCOE), this paper recommends professional development activities, which might be used by any district or school-site, featuring the use of a 25-minute film (Appendix A) consisting of focus group footage for the purpose of amplifying teachers' voices during the implementation of policy reforms.

As California has begun implementation of Common Core State Standards (CCSS), it is crucial that we maximize the potential for success and minimize the chances that we are merely doubling down on erroneous premises from previous attempts at reform. "The biggest potential pothole, by far, is failed implementation," claims Chester 
E. Finn Jr., president of the Thomas B. Fordham Institute (Hess \& McShane, 2014, p.1), and failed policies ultimately hurt students and teachers. One premise of implementation theory is that the success of any policy depends upon those people who make its details real in their work. While CCSS reform may be grand in scope, "implementation is ultimately a problem of the smallest unit" (McLaughlin, 1987): the classroom teacher, who must have sufficient capacity and will to realize CCSS goals. Some states can already serve as cautionary tales. In January of last year, the executive board of New York's teachers union unanimously voted, despite initial backing of CCSS, to withdraw its support for the standards until changes were made in the implementation plan. That February, Dennis Van Roekel, the president of the National Education Association, the country's largest teachers union, called the implementation of CCSS in many states completely botched... with seven of ten teachers believ[ing] that implementation of the standards is going poorly in their schools....teachers report[ing] that there has been little to no attempt to allow educators to share what's needed to get CCSS implementation right... Two thirds of all teachers report that they have not even been asked how to implement these new standards in their classrooms (Walker, 2014, para. 5).

The approach in California seems to have been much wiser than in many of the states where these objections are being raised, as implementation here has gone more slowly, allowing for greater teacher-inclusion. California adopted CCSS in 2010 and will make the first summative assessments operational this year. It has adopted a three-phase process targeting awareness, transition, and implementation, with the first two stages 
devoted, among other things, to establishing and expanding "collaborations" and providing professional learning opportunities for teachers (National, 2015). County offices of education, such SMCOE, have been tasked with helping their districts' schools align curricula and pedagogy to the CCSS.

SMCOE administrators are eager to maximize the success of implementation by fostering partnership between district administrators and teachers. According to Lori Musso, Administrator of Curriculum and Instruction Services for SMCOE, if CCSS “isn't approached as reform, it will be just another piece of paper on the wall - nothing will change... It is more about the mindset [of teachers and administrators] than anything else" (L. Musso, personal communication, January 4, 2013). SMCOE seeks to create collaborative professional development that might illuminate cultural dynamics ("mindset") arising during CCSS implementation, based upon the belief that successful policy implementation involves administrators understanding teachers' needs as much as teachers complying with expectations.

With this in mind, I began research with seven veteran colleagues in the Sequoia Union High School District (SUHSD), one of the districts SMCOE is assisting with CCSS implementation, with the goal of amplifying those teachers' voices. Veteran teachers play a critical role in shaping school cultures (Deal \& Peterson, 2009), and I was interested in hearing about CCSS in the context of the reforms they had experienced during their years of public high school teaching and in relation to their understanding of 
their most pressing professional responsibilities. I conducted interviews and then followed this up with a focus group, in which six of the seven teachers were able to participate. With these teachers' permission, I filmed the focus group, as the interview data suggested to me that a gathering of teachers like these, in the manner in which I organized them, might serve as a model for the kind of professional development needed, moving forward. All participants understood that this film could be distributed and used by SMCOE for professional development, with the aim of modeling a means to amplify all teachers' voices.

All of the teachers teach in SUHSD. Their years of experience range between 13 and 35 years. Two teachers have Ph.D.s. Two are English teachers and two teachers teach math. One is a Latin teacher, and another is now teaching art, but used to teach social studies. The film is divided into three parts: "Why We Teach," "Standards-based Reform," and "Professional Development." The professional development activity proposed below would begin with teachers viewing each segment and then having similar discussions of their own.

\section{The Film: "Time! Trust! Freedom!"}

The film has three central goals related to CCSS implementation and professional development: 
1) The film is meant to open up discussion, through the questions that the committed professionals participating in the film address. If this group of veteran teachers sometimes covers things not explicitly corresponding to the questions suggested in the professional development activity (below), that is because all of the Cohort I meetings I am proposing should also go in some directions of their own. The teachers in this film model professional seriousness, intellectual curiosity, and mutual respect, and these modes of engagement are what the professional development activity proposed below is really trying to motivate.

2) The film is meant to suggest, by modeling, that it is beneficial professionally for teachers to discuss policies, which despite their profound effects on teachers, are often debated without the initial conceptualization nor ongoing involvement of teachers. 3) The film is meant to suggest that teachers should bond socially more often, talking about policy and engaging intellectually about their shared work. The film is meant to suggest that increasing teachers' solidarity by mixing work and pleasure would be good for the professional identities of teachers and good for the profession itself.

\section{Research Foundation}

The CCSS professional development framework described in this paper is based upon my dissertation research and the relevant research literature presented in the first two papers in this collection. In addition, this paper relies on work done in the areas of 
problem and solution framing (Coburn, 2004, 2006), professional community learning theory (Wenger, 1998), and cornerstone tasks (McTighe \& Wiggins, 2012), as well as the current work of the professional development department of SUHSD.

\section{Narrative Inquiry}

The first paper in this collection addressing the impact of standards-based reform upon veteran teachers, is a form of narrative inquiry (Clandinin \& Connelly, 2000), wherein I explore my own experience teaching without standards, for 14 years in independent high schools, followed by 10 years of teaching in a California public high school. I explore the sense of diminished voice and agency I experienced in the first six years of teaching in public high school, at which time I began to question myself professionally, whereas in the independent schools my sense of efficacy and professionalism had increased every year. I considered the degree to which the independent school cultures had felt collectively focused upon meeting the needs of students as potential leaders, in need of skills central to critical thinking and creative, independent action, whereas the public school culture felt focused upon the faithful performance of given tasks, by both faculty and students. I also considered the contexts created by persons above and beyond all of us at the public school site, such as the policy-makers creating legislation like No Child Left Behind (NCLB), which shaped much of the administrative and faculty behavior of my first six years in public school, and the CCSS, which followed. 
I examined how, in the last four years, I had become more adept at modifying the pedagogy with which I had taught private school classes to fit the larger-sized classes I now taught, consisting of students with a greater range of academic, social, psychological, and emotional needs than I had worked with previously. I also noted that CCSS were introduced with the goal to deepen students' academic experiences, providing the kinds of critical thinking, creative problem-solving, and collaborative, interdisciplinary learning experiences that I thought my students in private school were getting, and which I had hoped to provide for public school students. With a renewed commitment to public education, I expressed my hope that CCSS implementation would be an opportunity for schools to shift their cultures away from a hierarchical management ethos, towards one focused upon pedagogy, where collective responsibility, democratically distributed leadership, and innovations for improved teaching and learning might arise from collaboration, critical thought, and creative problem-solving.

\section{Interviews and Focus Group}

The second paper in this collection relied on data from interviews of seven veteran SUHSD teachers and a filmed focus group with six of them, as I identified the following frames as salient, used by teachers to express the relationship between their work and CCSS at this moment in standards-based and accountability school reform:

Frame 1. Tools, not Rules: Teachers who see it as their professional responsibility to negotiate students' interests with the demands of institution, discipline, 
community, and state regard CCSS as tools to use, not necessarily rules to obey. Alignment with state standards may be a goal for them, but that is not a given.

Frame 2. Time for Collegial Support and Collaboration: Teachers seek the time to engage in "true learning" with each other; they often find evaluation, information, and guidance from non-teachers to be irrelevant to their professional development. Unreasonable demands upon time, such as those that come from large class sizes, impinge upon time they could use for collaborative planning.

Frame 3. Shutting the Door? Teachers are conflicted about their relationship with the world outside their classrooms and its impact on those classrooms. Feeling their profession is in danger, when reform is irrelevant to their work, they often feel they must "shut the door" to that outside world in order to focus on their professional responsibilities.

\section{Practical Implications for Professional Development}

\section{Problem Frames}

Research indicates that implementers' problem-framing is central to successful implementation (Coburn, 2006). District and site-level implementers have an interest in aligning the framing of problems related to CCSS implementation with those expressed by teachers. The interview data gleaned from the interviews and the focus group/film revealed the frames identified above in my research. These frames, in turn, suggest the 
following problem-frames. The proposal for professional development activity, which follows these problem frames in order to address them, also provides the means to better identify salience among all teachers' problem-frames at the site and district level.

Problem 1: These teachers want more time to plan with and learn from each other.

Problem 2: These teachers need self-determination in order to do the professional work they have undertaken, the negotiation of students' needs with institutional demands. They are generally happy to use CCSS as tools, but are concerned about the kind of testfocused micro-managed implementation seen during NCLB implementation that will lead to CCSS as limiting teacher autonomy and decision-making powers.

Problem 3: Most of these teachers are suspicious of motives and consequences relating to the standards-based and accountability reform movement of which CCSS are a part. Feeling that these policies have arisen out of mistrust of them and their work, some of these teachers are inclined to "shut the door" in order to focus on teaching.

To the extent that CCSS implementers at the district and school site level can frame professional development activities in response to the problem-frames identified above, my research indicates that this will improve the chances for successful implementation of CCSS and other reforms in the future. Addressing problem-frames 2 and 3, in particular, call for CCSS implementation itself to be framed as opportunity, rather than requirement, arising from problem-frames relating to students' needs, as 
opposed to teacher-deficiency. Administrators who address the problems articulated by teachers above invite teachers to join them as partners, serving students in new and more effective ways, with new levels of administrative support.

\section{SUHSD: Heading in the Right Direction}

With the exceptions of Liane Strub and Justine Rutigliano, the veteran teachers interviewed for this research are often critical of the professional development in their district, SUHSD. But it is important to note that Liane and Justine's positive reactions were to new professional development policies and that the critical comments from the other teachers were about professional development activities occurring in previous years. What I found particularly promising for SUHSD as a district is that the current professional development aligns with much of what the teachers in this research are requesting. While there are still many workshops that teachers are not leading, there are now many more, which teachers have been asked to lead, and it is far more common for them to offer their expertise. There is now far more teacher-participation in CCSS implementation, and other matters relating to pedagogy, than I experienced in the ten years I have been in the district.

The district has introduced several promising models for teacher collaboration and observation, including the formation of cohorts to devise curricula and observe other teachers (Appendix B). Cohorts are small, self-selected groupings of teachers in the 
same discipline. They volunteer to work with the district professional development office, which supplies funds, gives district approval, and provides training and tools for the groups to observe teachers at other sites and each other. Based on Japanese lesson study, the model asks teachers to collaborate to improve their own teaching. Being observed regularly, receiving feedback and guidance from peers, however, can be challenging for American teachers, as they are not generally as culturally or professionally accustomed to meeting collective expectations for conformity and public review as Japanese teachers generally are (Sisk-Hilton, 2009).

SUHSD District Instructional Coach Jessica Mass acknowledged that American teachers are more likely to want to go it alone and that the Cohort Model they adopted is in some respects an attempt to coax SUHSD teachers towards the kind of collective accountability, shared inquiry, and collaborative learning found in Japanese lesson study. Mass told me that the SUHSD professional development department understands the issues of trust teachers are dealing with, and that their goal is to reduce teachers' "insecurity about letting people in the classroom door" (J. Mass, personal communication, December 4, 2015). This comment resonated deeply with the research I had done, and seems to very directly respond to the third problem-frame I identified above. The reason for having teachers create their own cohorts is to increase trust. The hope, said Mass, is that once discussions about what happens when a teacher closes the door are initiated, collaboration might increase and lead to positive changes in pedagogy. 
These new directions of the SUHSD professional development department represent positive efforts to address the kind of concerns regarding standards-based educational reform raised by the teachers in this research, reflecting more trust in teachers' professionalism and attempting to increase teachers' capacity as pedagogues. Teachers are provided with what they need most - time - to work together and learn from each other. However, a district professional development department cannot change the structure of the workday or workweek, and so what they have to give teachers is limited in this regard. There are a very limited number of days that can be taken out of the year for all teachers, and after that, volunteer participants must make difficult choices about leaving classes in order to engage in these activities. The proposal below, which would involve the entire school community, attempts to take the cohort model one step farther, to potentially move school communities towards larger-scale changes.

\section{Proposal for Professional Development: The Double Cohort Framework}

\section{Goals}

The overarching goal of this professional development framework is to amplify teachers' voices in policy implementation to increase collective, collaborative responsibility for and improvement of the instructional core. With respect to CCSS, and with the intention of maximizing faculty and administrative frame-alignment, the immediate goals are to frame CCSS and their implementation as opportunities rather than 
requirements, to increase general awareness of strengths and weakness regarding CCSS implementation, and to generate and enact new curricula for meeting CCSS goals.

\section{Cohorts I and II}

This activity begins with a small self-selected group of teachers, as does the SUHSH Cohort framework described above (Appendix B). But similarities for the purposes of the present activity would end there (though a school site or a cohort could certainly choose to do the same work outlined in the SUHSD model, for further professional development, with release time). The small groupings which will constitute Cohort I in the Double Cohort framework are a response to problem frames 1 and 2, identified above, because they would provide teachers with the opportunity to unpack CCSSS, to learn from each other, to brainstorm innovative new ideas, and to identify common concerns. These cohorts are not voluntary - every member of the faculty and administrative staff would be asked to join a cohort. They would not necessarily involve teachers in the same discipline; they need only be teachers and administrators who choose to spend some time with each other.

The Cohort II's would be four or five times larger than Cohort I's and would be created with an eye to diversity of role (administrators and teachers), subject matter, experience, etc. Cohort II provides opportunities for ideas from Cohort I to find larger audiences and, perhaps, pathways to change existing policy or create new policies. This is 
a response to problem-frame 3, in that it increases teachers' participation in shaping the culture of their school and the conditions of their work.

The action steps described below are designed to happen once or twice a year (depending upon how well everyone decides the first one goes, as judged by the meeting following the Cohort II meetings) and to take place during two sessions: 1) a two hour gathering of Cohort I, at a site of that cohort's choice, where it is possible to watch and discuss the film "Time! Trust! Freedom!" and 2) a half-day of professional development, consisting of two hour-long meetings, at the school or district site - the first hour-long meeting gathers a number of Cohort I's together to share. The second hour-long meeting is of Cohort II's. The activity for Cohort I works in conjunction with the film (Appendix A). To maximize the success of all parts of the activity, teachers and administrators are expected to work in tandem in planning, implementing, and evaluating the proceedings.

\section{Double Cohort Framework Action Steps}

At least one month in advance of a school or district professional development half-day, time would be compensated for the following steps:

$\rightarrow$ Circulate the video, "Time! Trust! Freedom!" along with the following instructions, given to teachers:

1) Within the next week, please create a cohort of six to eight teachers (if you are an administrator, please create a cohort with other administrators). This is your Cohort I, which consists of colleagues you think you would enjoy meeting with all in your department or any mix of department-members. This is an opportunity to enjoy the company of your colleagues socially as well as professionally (as long as you are able to do both at the same time). If you have trouble forming a 
group, please get assistance from your district or school-site professional development coordinator.

2) In the next month, choose a time and place to gather with these colleagues, where there is the capacity to view the short film, "Time! Trust! Freedom!" and discuss and plan a reaction. Two hours will be compensated by the district.

3) Watch the first segment of the film, entitled, "Why We Teach," and discuss for 20 minutes. Address any or all of the following questions:

- What have you done or hope to do, as a teacher, about which you feel especially good? (looking backwards: best moments, looking forward: what do you still hope to accomplish?)

- What do you think the most important expectations are of a teacher - i.e., what defines professionalism for teachers in relation to: - students? Parents? Community/country? Yourself?

- Why do you hope someone would become a teacher? Are there certain traits that make for good, resilient, improving teachers?

- What have been the two or three most significant challenges in your professional life as a high school teacher?

- From where have you garnered the most strength, inspiration, and guidance in the face of challenges, during your career as a teacher?

4) Have someone take notes, audio-record, or film your discussion.

5) Watch the second segment of the film, entitled, "Standards-based Reform," and discuss for 20 minutes. Address any or all of the following questions:

- As we move forward with CCSS, what seem like reasonable hopes for positive changes, based upon the content of CCSS, and what (if anything) about CCSS content is triggering professional anxieties/concerns for you?

- What have been your reactions to CCSS implementation in your district to this point? What are the positive/promising aspects? Concerns? (consider district-wide, school-wide, and department-wide steps, as well as the observed behavior of self, colleagues, students, and parents to this point). 
- How do you plan to address CCSS expectations, moving forward, in your classroom? Do you have new ideas for new curricula?

- How can we maximize this opportunity for improvement of educational experiences for students? How can we increase cognitive and noncognitive positive engagement for students?

- In what ways could you work together with teachers in other disciplines to create new challenges for students that might have real-world applications, preparing them better for college and careers?

- How can we increase the focus of our school culture on teaching and learning? How can we work towards a collective sense of accountability for the improvement of our school's instructional core?

- Do you have any thoughts about school reform in the last two decades? Do you have opinions about the role of educators (teachers and administrators) in setting current educational policy, writ-large?

6) Have someone take notes, audio-record, or film.

7) Watch the third segment of the film, entitled, "Professional Development," and discuss for 20 minutes. Have someone take notes, audio-record, or film. Ask any or all of the following questions:

- What would you value most for professional development, moving forward? If you were in charge of PD for your district, and were given a mandate for radical change, what major kinds of resources would you ask for from the district, the schools, and the teachers? What activities would you initiate? What new areas would you explore?

○ What should we do, going forward (as teachers)? What do teachers everywhere need most? How can teachers increase their professionalism? What do teachers need to innovate - to solve the problems they face?

○ In a perfect world, what would our administrators do? Parents?

- What do we want academics, politicians, state authorities, interested donors, and corporations with a stake in education to do? 
8) Spend 30 minutes discussing commonalities, which emerged from discussions -hopes, concerns, student and teacher needs, new ideas.

9) Spend 30 minutes discussing some form of deliverable to bring to a larger gathering of teachers, to be held in a month. At a minimum, someone could read notes from the discussion, but groups are strongly encouraged to produce something that is a reflection of the group's time together which has aesthetic, as well as intellectual, value (in the same way that "Time! Trust! Freedom!" attempted to do that, with film). Optimally, the "deliverable" will not only have impact due to its content, but also due to its shape (a PowerPoint presentation, a reading, a sketch, a song, a picture...) which reflects the collaboration, discovery, and creative talents of the event as experienced by this particular cohort. In that way, the sharing of the deliverable elevates the discussion and becomes a way for all faculty and staff to better know each other. The presentation does not need to be comprehensive - it might highlight one or two key points or ideas that arise during the cohort discussion. In that way, salience is given to something identified by the group as significant.

10) Create action steps for the creation of this deliverable in time for the upcoming Cohort II meeting, and identify some person or persons as presenters.

11) At some point no later than one week before the upcoming professional development half-day, have the presenter submit a brief paragraph to the district or site professional development coordinator, identifying one or more central ideas dealt with during the cohort's discussion and in their "deliverable." The purpose for this is to help organize the first large group activity on the professional development half-day, with an eye towards diversity of theme.

\section{In further preparation for the district professional development half-day:}

$\rightarrow$ Professional development coordinator or site-based administrator creates a schedule for two hour-long meetings, and creates the groups for these meetings. The first of these meetings consists of six to eight cohort groups, put together by the PD coordinator or site administrator, with an eye towards diversity of themes. The PD coordinator or site administrator also creates the groups for the second meeting - these are Cohort II groupings. They should consist of from $24-40$ persons. Cohort II groupings are all about diversity of personnel, with Cohort I members split up and distributed among them, administrators grouped with teachers, different discipline teachers mixed together, younger teachers placed with older teachers, etc. 
On the school-site or district professional development half-day:

$\rightarrow$ In the first hour-long meeting, cohorts will present their deliverables to five to seven other cohort groups and discuss. Common hopes, concerns, and ideas are identified and everyone takes notes in order to present highlights in jig-sawed Cohort II groups, later.

$\rightarrow$ This is followed by Cohort II meetings (the second hour-long meeting). Cohort II's, as stated above, have a diversity of people from different Cohort I's, as well as administrators in them. This hour begins with a jigsaw; every person presenting regarding the deliverables seen and issues discussed in the half-day's first meetings.

Then this brief explanation of the Double Cohort Framework used is read and discussed:

"The intent of this Double Cohort Framework of professional development is for teachers to learn from each other and collaborate to solve problems related to pedagogy, and also to move information and ideas about educational policies up from the classroom, closer to people who shape those policies. If faculty and administrators decide that this has gone well, time could be given more regularly, throughout the year every year, to meet in cohorts of this type. Cohort I would be used to unpack and assess policy, and also to innovate curricula, while Cohort II would function to assess new ideas and help move valuable ones forward within larger contexts (school site, district, union, community, philanthropies, state and CCSS consortia, etc.). The goal here is not to find the single solution to the problems we face as educators, the goal is to create an enduring process for innovating, collaborating, and responding to students' needs, which also furthers teachers' professional self-determination."

After choosing a volunteer to take notes on the following and attend a follow-up meeting (it can be the administrator, but need not be), the cohort will discuss the following questions:

- Did any concerns, information, or ideas emerge from this activity that should be addressed? If so, what are they, who might best address or use them and who here will initiate contact?

- Might this Double Cohort framework be used next to develop Cornerstone Tasks for school sites? 
- Explanation for Cornerstone Tasks, by Jay McTighe and Grant Wiggins (2012), would be printed out and circulated:

Cornerstone Tasks are curriculum-embedded tasks that are intended to engage students in applying their knowledge and skills in an authentic and relevant context. Like a cornerstone anchors a building, these tasks are meant to anchor the curriculum around the most important performances that we want learners to be able to do (on their own) with acquired content knowledge and skills. Since these tasks are set in realistic contexts, they offer the natural vehicle for integrating the so-called 21 st century skills (e.g., creativity, technology use, teamwork) with subject area content knowledge and skills. They honor the intent of the Standards, within and across subject areas, instead of emphasizing only the content measured more narrowly on external accountability tests. These rich tasks can be used as meaningful learning experiences as well as for formative and summative purposes... Cornerstone tasks are designed to recur across the grades, progressing from simpler to more sophisticated; from those that are heavily scaffolded toward ones requiring autonomous performance. Accordingly, they enable both educators and learners to track performance and document the fact that students are getting progressively better at using content knowledge and skills in worthy performances. Like the game in athletics or the play in theater, teachers teach toward these tasks without apology (pp. 5-6).

- Is it a good idea to try something like this Double Cohort framework again? What are the potential risks and benefits?

- Is there a need to amplify the voices of teachers in policy reforms? If yes, are there better ways than this Double Cohort framework to involve teachers in CCSS implementation and other policy reforms?

$\rightarrow$ Follow up meeting (need not be conducted on this same professional development half-day): representatives from the Cohort II's meet to discuss steps forward. Many of these might be administrators. Principal and other top administrators should be present. 


\section{Other Recommendations for CCSS-Related Professional Development}

* Use Cohort I exactly as now used by SUHSD Professional Development department (Appendix B), but provide these cohorts with more institutional support. Build in time for them in the school week or month. Free up time for them by reducing the amount of time teachers are instructed or directed by administrative personnel or experts who are not their colleagues, and/or free up teachers' instructional time, regularly.

* To reframe CCSS as opportunity rather than requirement, avoid hierarchical structures and tones during their implementation, instead focus the energy of the school on pedagogy, establishing the primacy of the classroom and the authority of the teacher in the language used and the way new the standards are addressed. Avoid administrators or experts presenting information to larger groups, in favor of the collaborative unpacking of information among teachers, with those teachers' contributing disciplinespecific components and new ideas.

* Encourage and enable innovation that aligns with CCSS's most ambitious goals, by giving teachers the capacity to develop new curricula and activities that are interdisciplinary and critical, and which engage with the world outside the school. Seek answers regarding how to make this happen in the school day together with teachers, on an on-going basis. 


\section{Reflections}

The Double Cohort framework is meant to provide opportunities for teachers to experience what I did, while conducting this research: the honor and pleasure of learning from professional colleagues in an open-ended, and yet structured way. It relies upon a new appreciation for the importance of professional dialogue, per se, by creating what one of the focus group participants, Julie Marten, coined "think sessions," allowing teachers to freely explore concerns and new ideas. In his work on professional communities, Wenger (1998) found that both participation and reification (the formulation of policies) were necessary for the effective implementation of any new policy. The Double Cohort framework attempts to increase the participation of teachers in policy and collaborative innovation, by linking small groups to larger ones, and teachers to administrators, in new ways.

My hope is also that cohorts will enjoy the aesthetic challenge of presenting the data from their gatherings in novel ways; another aspect of this work that I enjoyed greatly. If the activity becomes a means to share diverse talents, with humor and individual style, that will increase the building of a sense of community and do much to create a larger dialogue, as works endure and impact larger groups of teachers, over time.

Finally, my hope is that administrators continue to seek engagement with teachers, such as Lori Musso at SMCOE courageously did by soliciting this proposal, intended to amplify teachers' voices. My narrative inquiry and selected data from the 
interviews can be interpreted as critical of the ways teachers are sometimes treated, but I hope that this can be heard and accepted as part of some teachers' experiences, without that leading to defensiveness or the refusal to listen. Nor is it my intention to strike a tone that is overly critical. We are truly partners and we unite as such, every day, in the service of students' needs and our professional advancement and growth. My intention is to help us do so to an even greater degree by opening up new channels for increased understanding and innovation. 


\section{References}

Clandinin, D. \& Connelly, F. (2000). Narrative inquiry: Experience and story in qualitative research. San Francisco, CA: Jossey-Bass.

Coburn, C. (2004). Beyond decoupling: Rethinking the relationship between the institutional environment and the classroom. Sociology of Education, 77(3), $211-244$.

Coburn, C. (2006), Framing the problem of reading instruction: Using frame analysis to uncover the micro-policies of policy implementation. American Educational Research Journal, 43(3), $343-379$.

Deal, T. \& Peterson, K. (2009). Shaping school culture: Pitfalls, paradoxes, and promises. San Francisco, CA: Jossey-Bass.

Hess, F. \& McShane, M. Ed.s (2014). Common core meets education reform. New York, NY: Teachers College Press.

McLaughlin, M. (1987). Learning from experience: Lessons from policy implementation. Educational Evaluation and Policy Analysis, 9(2),171 - 178.

McTighe, J. \& Wiggins, G. (2012). From common core standards to curriculum: Five big ideas. EduCore, $A S C D$. Retrieved at: http://educore.ascd.org/Resource/Content/d92b6a9f-c938-4fe6-94d1$\underline{6 f 6 b c 174 f a 89}$ 
National Governors Association Center for Best Practices and the Council of Chief State School Officers. (2015). Common Core State Standards Initiative. Retrieved at: http://www.corestandards.org/.

Sisk-Hilton, S. (2009). Teaching and learning in public: Professional development through shared inquiry. New York, NY: Teachers College Press.

Walker, T. (2014, February 19). NEA president: we need a course correction on common core. NEA Today. Retrieved at: http://neatoday.org/2014/02/19/nea-presidentwe-need-a-course-correction-on-common-core/.

Wenger, E. (1998). Communities of practice: learning, meaning, and identity. New York, NY: Cambridge University Press. 


\section{References (Papers $1-3$ )}

Bergquist, W. \& Pawlak, K. (2008). Engaging the six cultures of the academy.

San Francisco, CA: Jossey-Bass.

Bogdan, R. \& Biklen, S. (2007). Qualitative research for education: An introduction to theory and methods, ( $5^{\text {th }}$ ed.). Boston, MA: Pearson.

Boyle, T. C. (1996). Tortilla curtain. New York: Penguin Books.

Brodkey, J. (1986). Learning while teaching: Self-assessment in the classroom (Unpublished doctoral dissertation). Stanford University, Stanford, California.

California Department of Education. (2015). Common core state standards. Retrieved at: http://www.cde.ca.gov/re/cc.

California Department of Education. (2015). NGSS for California Public Schools, K 12. Retrieved at: http://www.cde.ca.gov/pd/ca/sc/ngssstandards.asp

Cherry-McDaniel, M. (2014). Coming full circle: A young teacher's journey with the standards movement. English Journal, 104(2), 93 - 98.

Clandinin, D. (2006). Narrative inquiry: A methodology for studying lived experience. Research Studies in Music Education, 27(1), 44 - 54.

Clandinin, D. \& Connelly, F. (1998). Stories to live by: Narrative understandings of school reform. Curriculum Inquiry, 28(2), 149 - 164.

Clandinin, D. \& Connelly, F. (2000). Narrative inquiry: Experience and story in qualitative research. San Francisco, CA: Jossey-Bass. 
Coburn, C. (2004). Beyond decoupling: Rethinking the relationship between the institutional environment and the classroom. Sociology of Education, 77(3), 211- 244 .

Coburn, C. (2006), Framing the problem of reading instruction: Using frame analysis to uncover the micro-policies of policy implementation. American Educational Research Journal, 43(3), 343 - 379.

Corona, B. (2013, November 22). More cracks in the core: Massachusetts halts common core implementation. The Daily Signal. Retrieved at: http://dailysignal.com/2013/11/22/cracks-core-massachusetts-halts-common-coreimplementation.

Crowther, F., Ferguson, M., \& Hann, L., (2009). Developing teacher leaders, $\left(2^{\text {nd }}\right.$ ed.): How teacher leadership enhances school success. Thousand Oaks, CA: Corwin Press.

Cuban, L. (2013). Inside the black box of classroom practice: Change without reform in American education. Cambridge, MA: Harvard Education Press.

Darling-Hammond, L. (2010). The flat world and education. New York: Teachers College.

Darling-Hammond, L. (2012). Creating a strong foundation for the teaching career. kappanmagazine.org. (94)3. Retrieved at: 
http://www.hfhighschool.org/assets/1/7/darlinghammond_the_right_start_pdk_nov_2012.pdf

Davies, R. (1981). The rebel angels. Toronto: Macmillan of Canada.

Deal, T. \& Peterson, K. (2009). Shaping school culture: Pitfalls, paradoxes, and promises. San Francisco, CA: Jossey-Bass.

Dewey, J. (1904). The relation of theory to practice in education. In The third yearbook of the National Society for the Scientific Study of Education: Part I: The relation of theory to practice in the education of teachers (pp. 9-30). Chicago, IL: University of Chicago Press.

Dewey, J. (1916). Democracy and education. New York, NY: Macmillan Company. Dewey, J. (1933). How we think. In Hickman, L. \& Alexander, T. (Eds.). (1998). The essential John Dewey, volume 1: Pragmatism, education, democracy. (pp. 274 277). Bloomington: Indiana University Press.

Elmore, R. (2008). School reform from the inside out. Cambridge, MA: Harvard Education Press.

Freire, P. (1970/2000). Pedagogy of the oppressed. New York: Continuum.

Giroux, H. (1996). Slacking off: Border youth and postmodern education. in Giroux, H., Lankshear, C., McLaren, P., \& Peters, M. (Eds.). (1996) Counternarratives: Cultural studies and critical pedagogies in postmodern spaces (pp. 59-80). New York: SUNY Press. 
Goffman, E. (1974). Frame analysis: An essay on the organization of experience.

Cambridge, MA: Harvard University Press.

Green, P. (2015, December 11). Duncan on ESEA: Still relentlessly wrong. Huffington Post, Education. Retrieved at: http://www.huffingtonpost.com/petergreene/duncan-on-esea-still-relentless-wrong b 8778996.html.

Guggenheim, D. (2010). Waiting for Superman. U.S.A.: Electric Kinney Films.

Halverson, E. R. (2010). Film as identity exploration: A multimodal analysis of youthproduced films. Teachers College Record, 112(9), 2352-2378.

Hanushek, E. (2102). Low-performing teachers have high costs. EducationNext, 4/26/2102. Retrieved at: http://educationnext.org/low-performing-teachers-havehigh-costs/.

Hargreaves, A. \& Shirley, D. (2012). The global fourth way: The quest for educational excellence. USA: Corwin Press.

Hess, F. \& McShane, M. Ed.s (2014). Common core meets education reform. New York, NY: Teachers College Press.

Hirschman, A. (1970). Exit, voice and loyalty: Responses to decline in firms, organizations, and states. Cambridge, MA: Harvard University Press.

Hulce, C., Hoehn, N., O'Day, J., \& Walcott, C. (2013). California and the common core state standards: Early steps, early opportunities. Washington, DC: American Institute for Research. 
Kamberelis, G. \& Dimitriadis, G. (2008). Focus groups: Strategic articulations of pedagogy, politics, and inquiry. In Denzin, N. \& Lincoln, Y. (Ed.s). Collecting and interpreting qualitative materials. Los Angeles, A: Sage Press.

Kirp, D. (2013). Improbable scholars. New York: Oxford University Press.

Kornfeld, J., Grady, K., Marker, P., \& Ruddell, M. (2007). Caught in the current: A selfstudy of state-mandated compliance in a teacher education program. Teachers College Record, 109(8), 1902-1930.

Lawrence-Lightfoot, S. (1983). The good high school: Portraits of character and culture. U.S.A.: Basic Books, Inc.

McGill, M. (2015). Race to the bottom; Corporate school reform and the future of public education. New York, NY: Teachers College Press.

McLaughlin, M. (1987). Learning from experience: Lessons from policy implementation. Educational Evaluation and Policy Analysis, 9(2),171 - 178.

McTighe, J. \& Wiggins, G. (2012). From common core standards to curriculum: Five big ideas. EduCore, $A S C D$. Retrieved at: http://educore.ascd.org/Resource/Content/d92b6a9f-c938-4fe6-94d1$\underline{6 f 6 b c 174 f a 89}$

Nash, R. (2004). Liberating scholarly writing. New York, NY: Teachers College Press. The National Commission on Excellence in Education. (1983). A nation at risk: The imperative for educational reform. Retrieved at: 
http://www2.ed.gov/pubs/NatAtRisk/index.html.

National Governors Association Center for Best Practices and the Council of Chief State School Officers. (2015). Common Core State Standards Initiative. Retrieved at: http://www.corestandards.org/.

Olsen, B. \& Sexton, D. (2009). Threat rigidity, school reform, and how teachers view their work inside current educational policy contexts. American Educational Research Journal, 46(1), 9 - 44.

Peck, C., Galluci, C., \& Sloane, T (2010). Negotiating implementation of high stakes performance assessment in teacher education: From compliance to inquiry. Journal of Teacher Education, 61(5), 451-463.

Phillips Exeter Academy. (2015). Harkness. Retrieved at: http://www.exeter.edu/admissions/109 1220.aspx.

Polkinghorne, D. (1988). Narrative knowing and the human sciences. Albany, NY: State University of New York Press.

Protheroe, N. (2008) The impact of fidelity of implementation in effective standardsbased instruction. Principal, September/October 38 - 41. Retrieved at: www.naesp.org

Ravitch, D. (2010). The death and life of the great American school system: How testing and choice are undermining education. New York: Basic Books.

Ravitch, D. (2013). Reign of error. New York: Knopf. 
Reddick, R. and Saenz, V. (2012). Coming home: Hermanos academicos reflect on past and present realities as professors at their alma mater. Harvard Educational Review 82(3), 353-380.

Russakoff, D. (2015). The prize: Who's in charge of America's schools? New York: Houghton Mifflin Publishing Company.

Saldana, J. (2013). The coding manual for qualitative researchers, (2 ${ }^{\text {nd }}$ ed.) London: Sage Publications, Ltd.

Schneider, M. K. (2015). Common core dilemma: Who owns our schools? New York, NY: Teachers College Press.

Seidman, I. (2013). Interviewing as qualitative research, $\left(4^{\text {th }}\right.$ ed.). New York, NY: Teachers College Press.

Sequoia Union High School District. (2015). Core understanding I. Retrieved at: www.seq.org/+uploaded/file_1978.pdf.

Shulman, L. (1983). Autonomy and obligation: The remote control of learning. In Shulman, L. (2004). The wisdom of practice: Essays on teaching, learning, and learning to teach. (pp. 503 - 520). San Francisco: Jossey-Boss.

Shulman, L. (1997). Professional development: Learning from experience. In Shulman, L. (2004). The wisdom of practice: Essays on teaching, learning, and learning to teach (pp. 133 - 162). San Francisco, CA: Jossey-Bass.

Shulman, L. (1998). Theory, practice, and the education of professionals. In Shulman, L. 
(2004). The wisdom of practice: Essays on teaching, learning, and learning to teach (pp. 511 - 526). San Francisco, CA: Jossey-Bass.

Sisk-Hilton, S. (2009). Teaching and learning in public: Professional development through shared inquiry. New York, NY: Teachers College Press.

Tyack, D. \& Cuban, L. (1995). Tinkering toward utopia; A century of public school reform. Cambridge, MA: Harvard University Press.

Vecellio, S. (2013). How shall I teach thee? An uncommon pedagogy for the common core. Schools: Studies in Education. 10(2), 222 - 242.

Walker, T. (2014, February 19). NEA president: we need a course correction on common core. NEA Today. Retrieved at: http://neatoday.org/2014/02/19/nea-president-weneed-a-course-correction-on-common-core/.

Wenger, E. (1998). Communities of practice: learning, meaning, and identity. New York: Cambridge University Press. 


\section{Appendix A}

Time! Trust! Freedom! (film)

Accompanying media found in Special Collections and Archives at San Francisco State University 


\section{Appendix B}

\section{SUHSD Cohort Model}

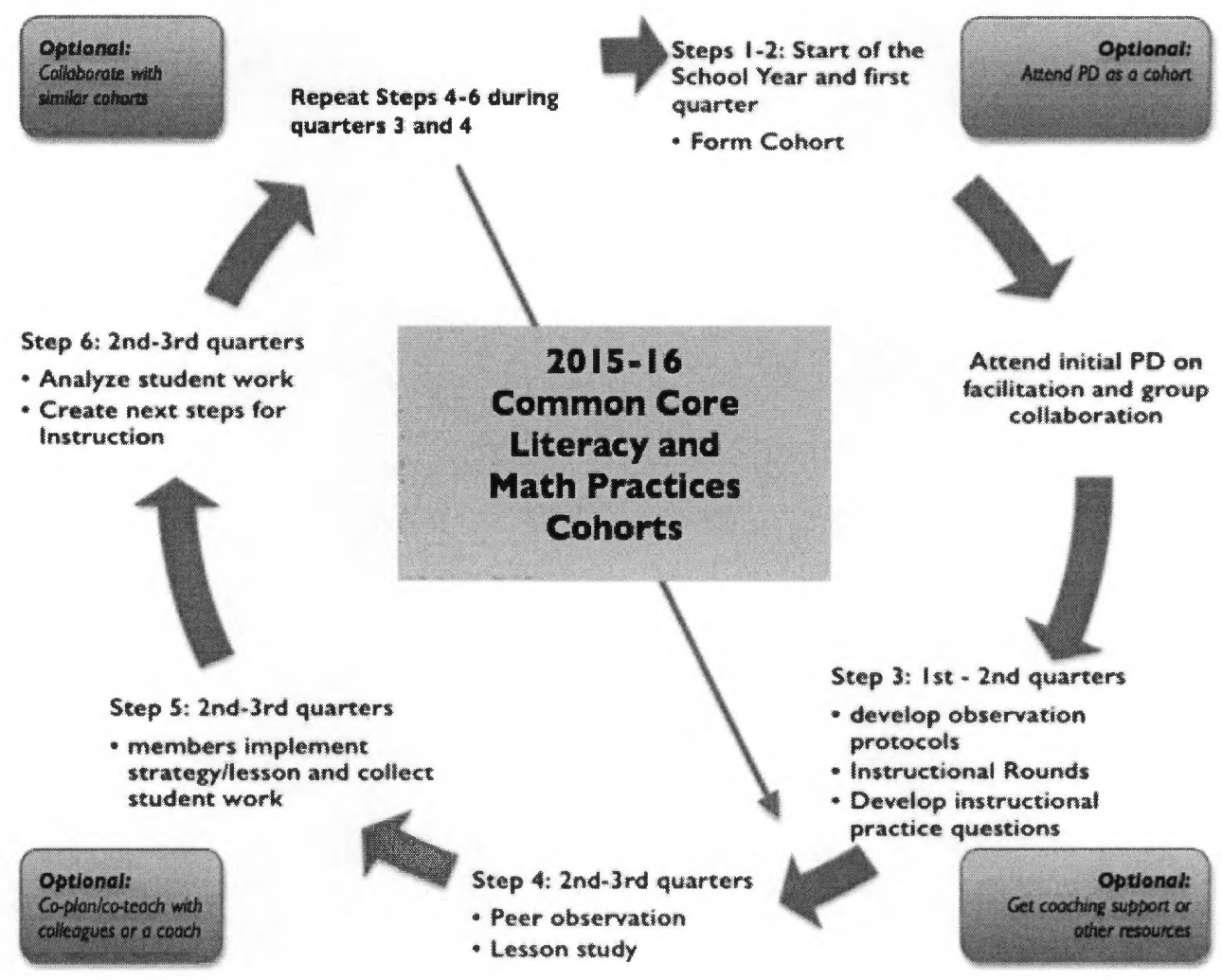

SUHSD Cohort Model for Professional Development:

Instruction-focused Groupings 


\section{Appendix C}

\section{Questions for Interviews}

Preliminary:

How long have you been teaching?

Why did you become a teacher?

Have your feelings about teaching changed in any ways over the years? If so, how and why?

As a teacher, what you think are your most significant responsibilities, vis-à-vis students? The community? The school? Yourself?

Where have you generally found direction or inspiration or guidance during your teaching career?

1. Tell me about the role of state-mandated standards in your teaching. To what extent do they clarify and guide you and your students? To what extent, if any, have they ever gotten in the way of what or how you thought you should be teaching?

2. How familiar are you with the Common Core State Standards (CCSS) in your subject area? How do you think your teaching will change by using them, as opposed to the previously-used California State Standards?

3. What are your hopes and concerns, regarding CCSS objectives in your classroom? To what extent do your own objectives as a teacher align with what you perceive as CCSS objectives?

4. Can you speak about your comfort, regarding the capacity you now have and believe you will continue to be given, in order to meet the new expectations from CCSS standards? To what extent do you think your current students' capabilities, the schools' resources, administrative support, and ongoing professional development time and activities will enable you to meet new expectations? 
5. What kinds of professional development would you find most useful now and in the future, to help you implement and continue to maintain CCSS successfully, on an on-going basis?

6. What role do you think CCSS should have in the assessment of your teaching?

7. To what extent do you feel you had a voice in the development of CCSS and now have a voice in their implementation? To what extent do you feel you should have any or a greater voice in CCSS development and implementation? To what extent do you feel teachers' needs and wishes, in general, were well represented in CCSS development and will continue to be a critical component of implementation? 


\section{Appendix D}

\section{Questions for Focus Group}

(Hors d'oeuvres and drinks) Defining the teacher's role:

- What have you done or hope to do, as a teacher, about which you feel especially good? (looking backwards: best moments, looking forward: what do you still hope to accomplish?)

- What do you think the most important expectations are of a teacher i.e., what defines professionalism for teachers in relation to: students? Parents? Community/country? Yourself?

- Why do you hope someone would become a teacher? Are there certain traits that make for good, resilient, improving teachers?

- What have been the two or three most significant challenges in your professional life as a high school teacher?

- From where have you garnered the most strength, inspiration, and guidance in the face of challenges, during your career as a teacher?

(Dinner) School reform in the context of a life of teaching:

- Are state-mandated standards necessary? Helpful? Intrusive? Counter-productive? How did your experiences teaching pre-CA standards compare to teaching with CA standards?

- Common Core State Standards (CCSS): To what extent have you experienced any changes, as we begin the adoption of CCSS? What seem like reasonable hopes for positive changes, based upon the content of CCSS, and what (if anything) about CCSS content is triggering professional anxieties/concerns for you?

- Reactions to CCSS implementation in SUHSD to this point: positive/promising aspects? Concerns? (consider district-wide, school-wide, and department-wide steps, as well as the observed behavior of self, colleagues, students, and parents to this point) 
- How do you plan to address CCSS expectations, moving forward, in your classroom? What are your hopes and dreams regarding support from district and school administration for your efforts?

- What would you value most for professional development, moving forward? If you were in charge of PD for your district, and were given a mandate for radical change, what major kinds of resources would you ask for from the district, the schools, and the teachers? What activities would you initiate? What new areas would you explore?

- Big picture: School reform in the last two decades: reactions to NCLB and the political and corporate involvement in recent reforms. Opinions about the role of educators (teachers and administrators) in setting current educational policy, writ-large.

(Dessert) The future:

- What should we do, going forward (as teachers)? What do teachers everywhere need most? How can teachers increase their professionalism? What do teachers need to innovate - to solve the problems they face?

- In a perfect world, what would our administrators do? Parents?

- What do we want academics, politicians, state authorities, interested donors, and corporations with a stake in education to do? 